BULLETIN Bulletin hispanique

HISPANIQUE Université Michel de Montaigne Bordeaux

117-1 | 2015

Les poètes des rhéteurs

\title{
Ideas retóricas de Manuel Ponce a propósito de las Soledades
}

Antonio Azaustre Galiana

\section{(2) OpenEdition}

1 Journals

\section{Edición electrónica}

URL: https://journals.openedition.org/bulletinhispanique/3754

DOI: 10.4000/bulletinhispanique.3754

ISSN: 1775-3821

\section{Editor}

Presses universitaires de Bordeaux

\section{Edición impresa}

Fecha de publicación: 1 junio 2015

Paginación: 65-94

ISBN: 979-10-300-0174-7

ISSN: 0007-4640

\section{Referencia electrónica}

Antonio Azaustre Galiana, «ldeas retóricas de Manuel Ponce a propósito de las Soledades», Bulletin hispanique [En línea], 117-1 | 2015, Publicado el 01 junio 2018, consultado el 11 febrero 2022. URL: http://journals.openedition.org/bulletinhispanique/3754 ; DOl: https://doi.org/10.4000/ bulletinhispanique.3754 


\title{
Ideas retóricas de Manuel Ponce a propósito de las Soledades
}

\author{
Antonio Azaustre Galiana \\ Universidad de Santiago de Compostela ${ }^{1}$
}

Ce travail étudie les idées rhétoriques que Manuel Ponce développe dans ses annotations à la Première Solitude de Góngora et dans son Discours en défense de l'obscurité en poésie. Il apporte, par ailleurs, de nouveaux éléments sur le manuscrit qui contient ces textes de Ponce, découvert par Dámaso Alonso en 1978.

Mots-clés : Manuel Ponce, Góngora, Soledades, commentaire philologique.

Este trabajo estudia las ideas retóricas que Manuel Ponce desarrolla en su anotación a la Soledad primera de Góngora y en su Discurso en defensa de la oscuridad en la poesía. Además, ofrece nuevos detalles sobre el manuscrito que contiene esos textos de Ponce, y que fue descubierto por Dámaso Alonso en 1978.

Palabras clave: Manuel Ponce, Góngora, Soledades, comentario filológico.

This paper studies the rhetorical ideas Manuel Ponce develops in his annotation to Soledad Primera by Góngora and in his Discurso on the defence of obscurity in poetry. It furthermore offers new details on the manuscript, found by Dámaso Alonso in 1978, that contains those texts by Ponce.

Keywords: Manuel Ponce, Góngora, Soledades, Philological Comment.

1. Este trabajo se integra en las actividades de los Proyectos de Investigación "El comentario filológico hispano en los siglos XV a XVII: estudio y edición" (FFI2010-16903) y "El comentario filológico en el ámbito hispano entre los siglos XIII y XVII” (FFI2013-42357-P). 
$\mathrm{M}$ anuel Ponce es una de esas figuras no demasiado conocidas en la erudición literaria del siglo XVII. Los pocos datos que sobre él y su obra conservamos deben ser tomados con ciertas dudas y reservas ${ }^{2}$. Parece que nació en Madrid hacia $1591^{3}$, y vivía aún en 1623. Esta última referencia se apoya en uno de los muchos textos de censura que suscitó el Elogio descriptivo a las fiestas que la Majestad del Rey Felipe IV hizo por su persona en Madrid a 21 de agosto de 1623, escrito por Juan Ruiz de Alarcón con la colaboración de otros autores. La censura en cuestión es el Comento contra 73 estancias que don Juan Ruiz de Alarcón ha escrito..., atribuido a Quevedo y donde figura el nombre de Manuel Ponce como autor de cuatro de esas estancias ${ }^{4}$.

Su obra conocida hasta hoy es la siguiente:

- La Sylva a las Soledades de don Luis de Góngora. Con anotaciones y declaración por Manuel Ponce, y un discurso en defensa de la novedad y términos de su estilo. Noviembre de 1613, texto descubierto y estudiado por Dámaso Alonso5.

- Una epístola al conde de Villamediana en defensa del léxico culterano, que estudiaron y editaron Juan Manuel Rozas y Antonio Quilis ${ }^{6}$, y que fechan en torno a 1617.

- Oración fúnebre a la muerte de don Rodrigo Calderón, que fue degollado en la Plaza Mayor de Madrid, Jueves 21 de Octubre de 1621.

- Relación de las fiestas que se han hecho en esta Corte a la canonización de cinco santos: copiada de una carta que escribió Manuel Ponce en 28 de Junio, 1622...

2. Los datos que siguen sobre la figura de Ponce fueron ya expuestos en Azaustre y De Carlos (2010).

3. Entrambasaguas (1967: II, 92) indica que el 8 de noviembre de 1622 tenía 31 ańos. Esta información procede de la documentación que consultó a propósito de las entrevistas que se hicieron a diversos conocidos de Pedro Torres Rámila -amigo de Ponce- a fin de decidir sobre la solicitud de Torres Rámila de una de las becas vacantes en el Colegio de San Ildefonso, en Alcalá. Más datos sobre su vida y obras pueden consultarse en Entrambasaguas (1967: I, 335); Rozas y Quilis (1961); Alonso (1982) y Osuna Cabezas (2008: 115-123).

4. Señaló el dato Dámaso Alonso (1982: 504).

5. Véase Alonso (1982). Egido (1989: 37) ha subrayado la importancia de la temprana fecha de esta defensa gongorina en el panorama de la silva en el Barroco. Véanse también las precisiones cronológicas de Alonso (1982: 520-524), Iglesias Feijoo (1983: 185), Jammes (1994: 616-618) y Osuna Cabezas (2008: 111-115). Nombro el conjunto del texto como Sylva a las Soledades, como ya hiciera en su día Dámaso Alonso. El sintagma puede leerse entendiendo sylva como «escrito que reúne varios materiales concernientes a las Soledades». Pero, analizando el conjunto de la portada, también puede interpretarse que Sylva a las Soledades es la manera que Ponce tiene de referirse al poema de Góngora, pues, tal y como señala la portada, el manuscrito se inicia con el texto de la Soledad primera, al que siguen la anotación y explicación de sus versos, y el discurso en defensa de la oscuridad. Además, en varias ocasiones, Ponce se refiere al poema de Góngora como silva; Jammes (1994: 617) ya advirtió sobre esta particularidad del título.

6. Véase Rozas y Quilis (1961: 412-413) para los problemas de autoría de esta epístola, que en su encabezamiento lleva escrito "A Manuel Ponçe S. P. D.». Rozas y Quilis ven a Villamediana tras diversas alusiones al destinatario de la carta (alusiones al Faetón, tratamiento de señoría...), y advierten que la letra A que encabeza el epígrafe fue añadida posteriormente por una mano diferente a la que copió el manuscrito. Gutiérrez Arranz (2001: 9-10) también señala esta obra de Ponce en su estudio de la mitología en Villamediana. 
- El soneto "Una Aurora esplendor de siete Auroras», editado por Lope de Vega en su Relación de las fiestas que la insigne villa de Madrid hizo en la canonización de su bienaventurado hijo y patrón, San Isidro... Madrid, 1622. - La Apología en defensa de Virgilio sobre un lugar de la cuarta Geórgica, por Manuel Ponce, dirigida al Maestro Pedro de Torres Rámilla, colegial en el insigne theólogo de Alcalá, texto que encontré en la Hispanic Society, y que Helena de Carlos y yo mismo transcribimos y estudiamos en 2010. Este texto confirma la noticia que Quevedo había dado en su Perinola; allí señalaba un libro de Ponce "comentando algunos lugares difíciles de Virgilio" (Perinola, p. 506) entre los olvidos de Juan Pérez de Montalbán en su Índice o catálogo de los ingenios de Madrid, incluido al final del Para todos (1632).

Manuel Ponce fue un estudioso muy activo en las diversas polémicas literarias que poblaron las letras españolas del siglo XVII.

Así, la Apología en defensa de Virgilio, de 1622, se encuadra en la rica tradición de comentarios al poeta mantuano que se desarrolló en Espańa, y se dirige en forma de carta a Pedro de Torres Rámila, con quien Ponce mantuvo una relación de amistad y afinidades literarias ${ }^{7}$. En la Spongia, además de criticar a Lope de Vega, Torres Rámila había atacado a Juan Luis de la Cerda por sus comentarios a Virgilio ${ }^{8}$. Juan Luis de la Cerda fue uno de los autores que defendieron a Lope de Vega en la Expostulatio Spongiae, lo que confirma su antagonismo con el grupo de Ponce y Torres Rámila.

Las características del texto de Manuel Ponce responden a la evolución que los comentarios de Virgilio experimentaron en nuestras letras a partir del siglo $\mathrm{xv}^{9}$. En este proceso, la finalidad eminentemente propedéutica del comentario se enriqueció con un mayor sentido crítico y una mayor preocupación filológica por el texto comentado. Este no será solo una base que permita aprender gramática latina, retórica, historia o realia, sino que su propia configuración se convertirá en objeto de estudio. El comentario de Manuel Ponce responde a esta orientación, pues su objetivo es la correcta fijación de un pasaje virgiliano. No es, pues, el tipo de comentario general que atiende a la totalidad de la obra y la explica línea a línea. Se trata de un comentario más especializado, cuyo destinatario es un experto en la materia; su finalidad es explicar algún lugar del texto especialmente difícil, matizando o refutando con frecuencia propuestas anteriores ${ }^{10}$. Esto es precisamente lo que hace Manuel Ponce al dirigir a Pedro de Torres Rámila su refutación de la lectura que Juan Luis de la Cerda hacía de

7. De ellas da cuenta por extenso Entambasaguas (1967: I, passim).

8. Véase Entrambasaguas (1967: I, 339 y ss.).

9. Véanse al respecto, entre otros, Codoñer (1997: 33) y Jiménez Calvente (2001).

10. Jiménez Calvente (2001: 46-49) señala diversos ejemplos de este tipo de comentario; entre los primeros títulos están Filippo Beroaldo con sus Annotationes contra Servium (1482) y Poliziano con su Miscellanea (1489). Mazzochi (1993) estudia los planteamientos estéticos, ideológicos y culturales del Barroco que pasaron al comentario virgiliano de Juan Luis de La Cerda. 
los versos 287-294 de la cuarta Geórgica ${ }^{11}$, pasaje donde Virgilio habla del Nilo y las tierras de Egipto y ambienta la ubicación de la práctica de la bugonia, es decir, la generación espontánea de abejas a partir de la carne de bueyes muertos.

La figura de Manuel Ponce también aparece en las polémicas literarias que enfrentaron a Lope de Vega con los preceptistas aristotélicos ${ }^{12}$. Los hitos de esta discusión se hallan en dos textos. El primero lleva el gráfico título de Spongia: criticaba las diferentes obras de Lope y fue publicado por Pedro de Torres Rámila en 1617; el segundo, la Expostulatio Spongiae, es la respuesta que varios amigos del Fénix editaron pocos meses después ${ }^{13}$. La participación de Manuel Ponce en la Spongia se vincula a la del mencionado Torres Rámila, con quien, como hemos dicho, le unían una buena relación y comunes puntos de vista literarios.

La Sylva a las Soledades y la epístola al conde de Villamediana sitúan a Manuel Ponce como defensor de Góngora y el estilo culto, dentro de la polémica que protagonizó el panorama literario de las primeras décadas del xvii. Almansa y Mendoza, el Abad de Rute y Martín de Angulo y Pulgar lo habían citado ya entre los defensores del poeta cordobés ${ }^{14}$.

La epístola a Villamediana se centra sobre todo en el neologismo o, como se denominaba en su época, las verba peregrina. Frente a las censuras que achacaban a este uso el atentar contra la proprietas, Ponce argumenta en su defensa apoyándose en autores latinos y romances que emplearon dichos vocablos, y señalando que es un fenómeno común a todas las lenguas. Además, niega que se trate de una vana ostentación erudita, y defiende la necesidad artística de dichas voces "para significar mejor o con más decencia sus conceptos»"

La Sylva a las Soledades fue dada a conocer por Dámaso Alonso quien, informado por José Antonio Muñoz Rojas, consultó el manuscrito de la biblioteca de don Francisco Fernández de Navarrete, marqués de Legarda, en Ávalos (Logroño). En un trabajo de 1978, Dámaso Alonso estudió sus características generales y editó algunos pasajes. En estas páginas intentaré

11. La primera edición de obra virgiliana con comentario de Juan Luis de la Cerda, «Ex collegio Paltheniano", Madrid, data de 1608 y comprende solo Bucólicas y Geórgicas. Ediciones posteriores incluyen la Eneida: Lyon, Horace Cardon, 1612-1619 y Colonia, 1628. Véase Piccirillo (1985: 169-178).

12. Para más detalles sobre esta polémica, véanse el panorama histórico y los documentos que ofrece Entrambasaguas (1967), y los estudios y ediciones de Tubau (2007 y 2008).

13. Aunque, recientemente, González Barrera (2011: 75-85) ha defendido que el contexto de esa polémica no sería el cumplimiento o no de los preceptos neoaristotélicos por parte de Lope, sino desacreditar a Lope aprovechando la fama de Góngora en el ambiente de polémica que generaron sus poemas.

14. El Abad de Rute lo mencionó en su Examen del Antídoto (p. 419), de 1617; Angulo y Pulgar en sus Epístolas satisfactorias, f. 54, editadas en 1635; Almansa lo hizo en sus Advertencias (en Orozco, 1969: 198-199), donde critica a quienes censuran la poesía de Góngora sin tener conocimientos para ello y señala los escasos ingenios que a su juicio podrían acometer esta tarea; entre ellos, Manuel Ponce. Dámaso Alonso (1982: 505) ya había indicado estas referencias. Sobre la participación de Ponce en estas polémicas, véase también Roses Lozano (1994: 20-22).

15. Véase Rozas y Quilis (1961: 416 y 421). 
continuar esa línea centrándome en las ideas retóricas de Ponce, como paso previo a una edición del texto de su manuscrito, cuya consulta y reproducción fotográfica me ha permitido amablemente su actual propietario para este fin (por expreso deseo suyo no menciono su nombre).

Tras la portada y una breve semblanza de la vida y obras de Ponce (probablemente escrita por el propio Dámaso Alonso), el contenido del manuscrito es el siguiente:

ff. 2r-3r: Dedicatoria «A los que no entienden esta silva».

ff. 4r-33v: Texto de la Soledad primera.

ff. 34r-40r: Dedicatoria «Al conde de Salinas, Presidente del Consejo Supremo de Portugal».

ff. 40v-83r: Anotación al poema.

f. 83v: nota de Ponce: «Intelligisti cogitationes meas de longe. Ps. 138».

f. 84r: Anotación de Ponce donde recoge diversos autores que trataron sobre el Nilo además de los que señala en sus notas al poema.

f. $84 \mathrm{v}$ : en blanco.

ff. 85r-108v: Discurso en que se trata si en los términos de la poesía es necesaria la obscuridad y forzosa en las locuciones della. Y en qué modo se puede permitir que el Poeta sea obscuro a los ignorantes de los preceptos del Arte; y facultades que se cifran en los versos. $Y$ si el que a todos es difícil se haya de reprobar y no estudiarle. (f. $85 \mathrm{r}$ : portada del Discurso, f. 85v: en blanco, ff. 86r-86v: Dedicatoria al conde de Salinas, ff. 87r-108v: texto del Discurso).

ff. 109r-109v: Apéndice donde remite al prólogo de la Coronación de Juan de Mena, y recoge algunos de sus pasajes para autorizar los usos gongorinos.

ff. 110r-112r. La Rosa. Od. 53 de Anacreón traducida del griego por don Francisco de Quevedo.

f- 112v: en blanco.

ff. 113r-120v: Texto de la Segunda Soledad, El periodo de la caza, desde el verso 677 («Las Horas ya, de números vestidas») hasta el verso 936 («heredado en el último graznido»).

f. 121: en blanco.

El manuscrito se encuentra en buen estado de conservación. Sus dimensiones son 150 x $120 \mathrm{~mm}$. y consta de 121 folios numerados a lápiz por el propio Dámaso Alonso (1982: 506). Como él mismo indica, existen restos de la numeración anterior de dos secciones del manuscrito, ambas empezando por el folio primero, y hay también otra parte que carece de foliación. Las dos secciones con foliación original son las siguientes:

1) Foliación original que numera consecutivamente la dedicatoria al conde de Lemos que precede a la anotación de la Soledad primera y las notas de Ponce a este poema. Esta numeración puede leerse desde el folio 2 (f. 35r de la moderna) hasta el folio 50 (f. 83r de la moderna).

2) Foliación original desde el folio $1 \mathrm{al} 22$ (ff. 87r-108r en la moderna) que se corresponde con el texto del Discurso en defensa de la oscuridad. En este caso, la dedicatoria al conde de Salinas que precede al texto no lleva numeración original, por lo que cabe pensar que fue redactada en otro momento. 
La encuadernación del volumen ha cortado los bordes de algunos folios, e impide leer con claridad algunas de las anotaciones marginales y algunos números completos de la foliación original. La firma de Ponce aparece en tres ocasiones: tras las dos dedicatorias al conde de Salinas, la que precede a la anotación del poema (f. 40r) y la que precede al Discurso sobre la oscuridad en poesía (f. 86v), y al final de la anotación de la Soledad primera (f. 83r).

En cuanto a la letra del manuscrito, hay que diferenciar tres manos. Una sería la que copia el texto de la Soledad primera ${ }^{16}$ (véase la imagen 1 en la página siguiente); otra la de Ponce, que copia la anotación al poema, el Discurso en defensa de la oscuridad, los versos de la Soledad segunda y los textos situados en apéndice al final del manuscrito (imagen 2). Así lo muestra, por ejemplo, el examen detenido del diferente trazo predominante en letras como $p r g M$. Además, el cambio entre una y otra mano, entre el final de la Soledad primera y el comienzo de la anotación (ff. 33v y 34r), parece coincidir con un cambio de cuaderno (imagen 3). En todo caso, un examen más detenido del papel y sus filigranas -que aún no he podido llevar a cabo- confirmaría estos extremos ${ }^{17}$. Que sea la mano de Ponce lo indica la coincidencia de esa letra con la de la firma que aparece en los ff. 40r, 83r y 86v (imagen 4). La tercera mano, muy claramente diferenciada, es la de un estudioso que leyó el trabajo y anotó algunas enmiendas a los versos de la Soledad primera incorporando variantes de la versión definitiva; también incorporó observaciones a las notas de Ponce, a las que este replica en algún caso, lo que indica que el texto volvió a sus manos tras esa revisión (imagen 5$)^{18}$.

Esta diferenciación en las grafías concuerda con los restos de una foliación originaria del manuscrito que, como se ha dicho, numera del folio 1 al 50 la anotación al poema, y del 1 al 22 el texto del Discurso sobre la oscuridad, partes ambas escritas por Manuel Ponce (imágenes 6 y 7). Todo ello confirma la propuesta de Dámaso Alonso, seguida por Jammes, de que el trabajo de Ponce se llevó a cabo en varias fases, lo que nos lleva al asunto de la fecha.

Esta obra de Ponce es considerada uno de los primeros comentarios a las Soledades de Góngora, aunque presenta problemas de datación. La portada del manuscrito refleja la fecha de noviembre de 1613, rasgo que concuerda con la tendencia de Manuel Ponce a fechar con precisión sus escritos. Esa portada se refiere tanto a la anotación del poema como al Discurso, por lo que cabe pensar

16. Los números que acompañan al texto de la Soledad primera, y que se corresponden con las notas de Ponce, fueron escritos por el propio Ponce. También los números de la foliación original de algunas partes del manuscrito, señaladas arriba.

17. Agradezco a Ana Suárez González, paleógrafa de la Universidad de Santiago de Compostela, su experto asesoramiento en estas cuestiones.

18. Hay, además, una anotación de otra mano diferente a las tres señaladas. Esta anotación, que puede verse en la imagen 3, aparece en el f. 33v y recoge uno de los Avisos de amigo del barcelonés Joaquín Setantí (c. 1540-1617), considerado representante del tacitismo y el aforismo sentencioso: «Auiso VI Joachin Setantí. / No seas inuentor de cosas nuebas, / ni las antiguas aprouadas mudes». La letra de esta anotación podría ser incluso del XVIII. Más detalles sobre Setantí en Blanco (2006). 


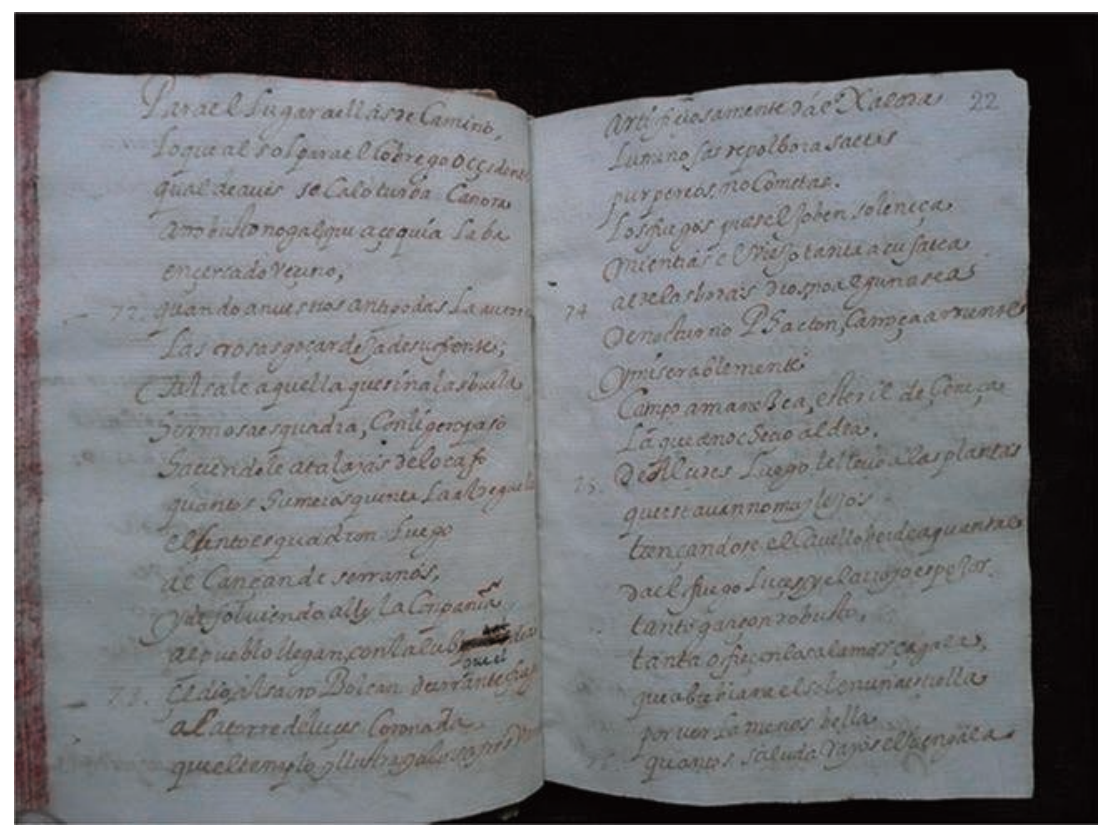

Imagen 1

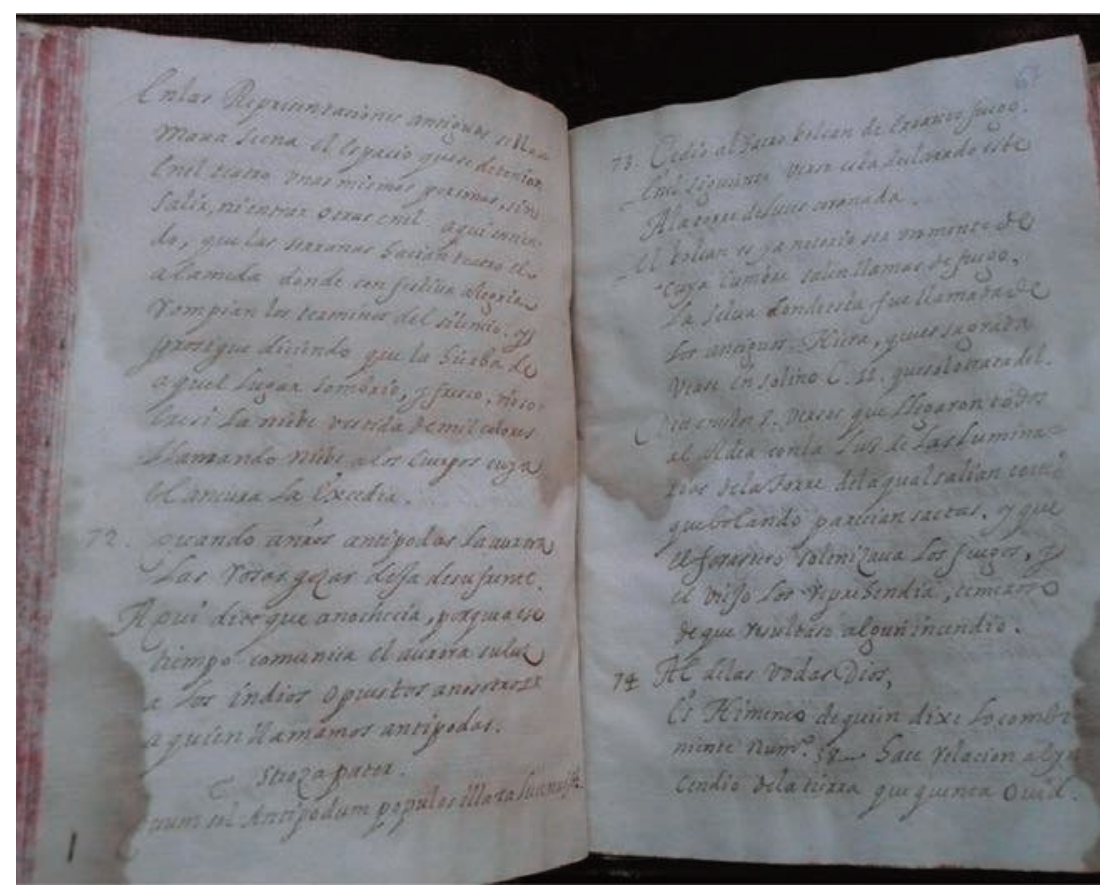

Imagen 2

Sylva a las Soledades de Don Luys de Gongora. Con anotaciones y declaracion por Manuel Ponce, y un Discurso en defensa de la Novedad y Terminos de su estilo. Noviembre de 1613. Manuscrito de propiedad particular 


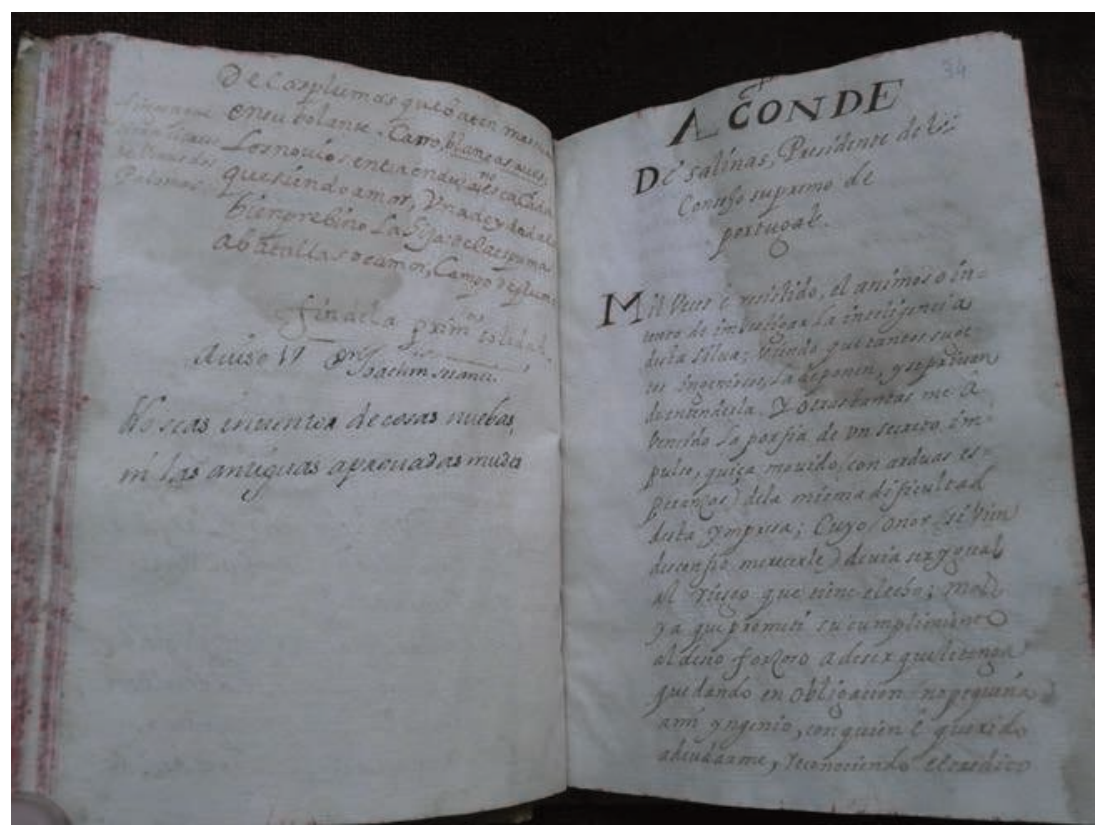

Imagen 3

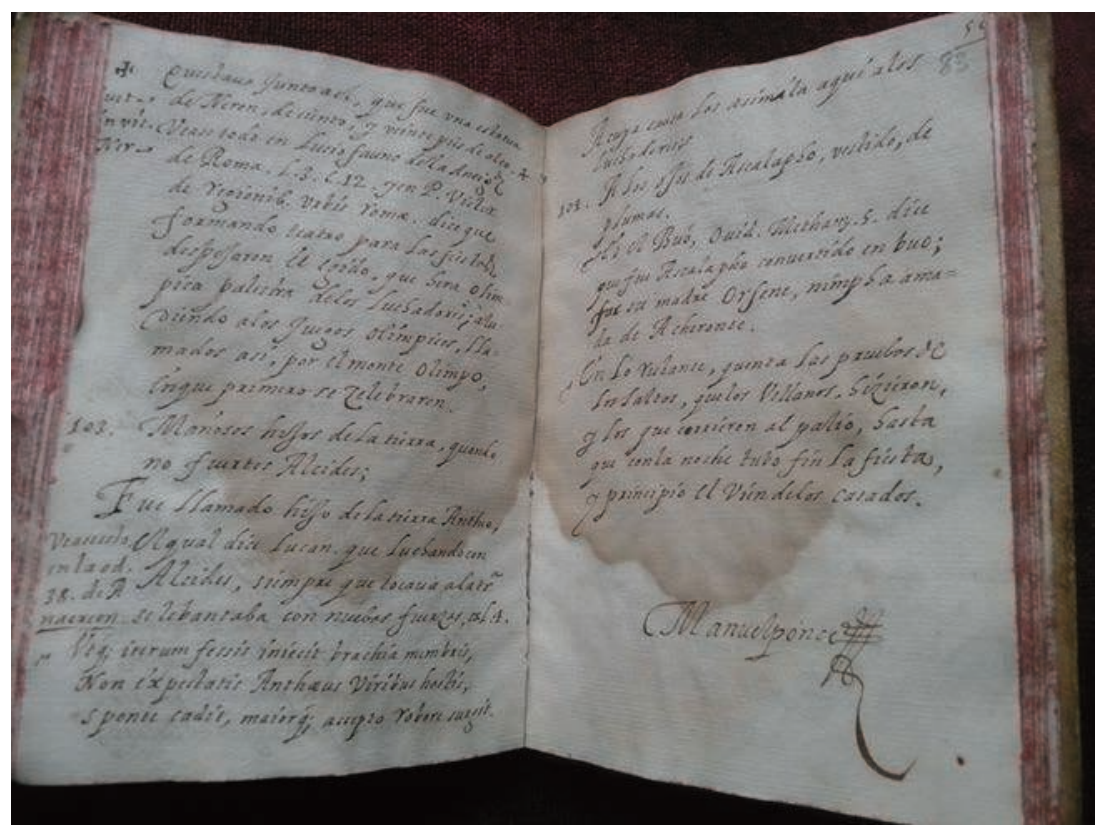

Imagen 4

Sylva a las Soledades de Don Luys de Gongora. Con anotaciones y declaracion por Manuel Ponce, y un Discurso en defensa de la Novedad y Terminos de su estilo. Noviembre de 1613. 


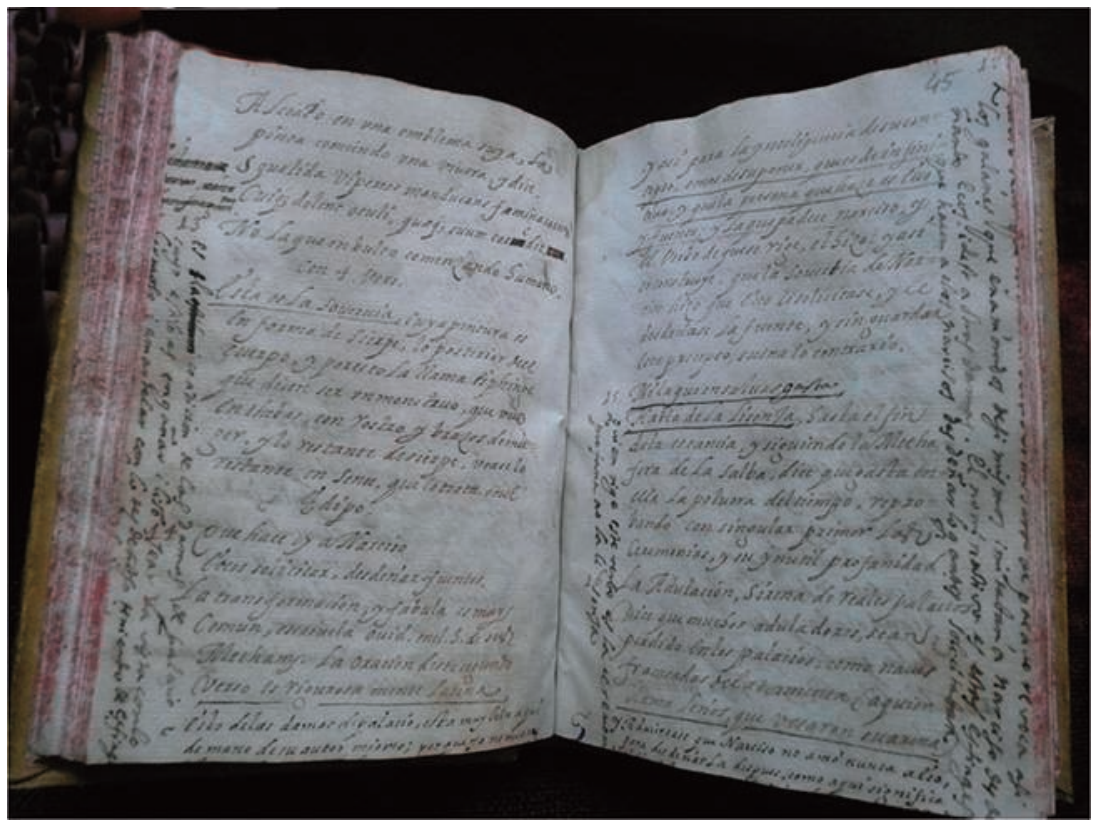

Imagen 5

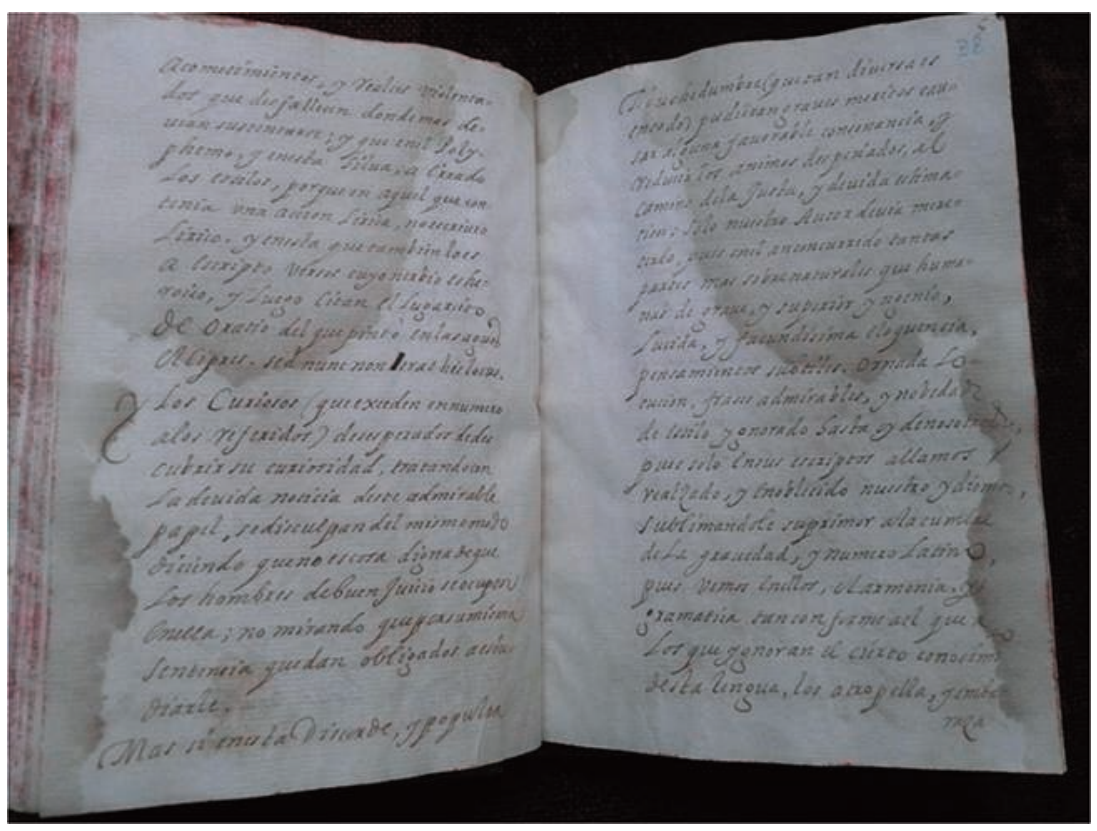

Imagen 6

Sylva a las Soledades de Don Luys de Gongora. Con anotaciones y declaracion por Manuel Ponce, y un Discurso en defensa de la Novedad y Terminos de su estilo. Noviembre de 1613. 


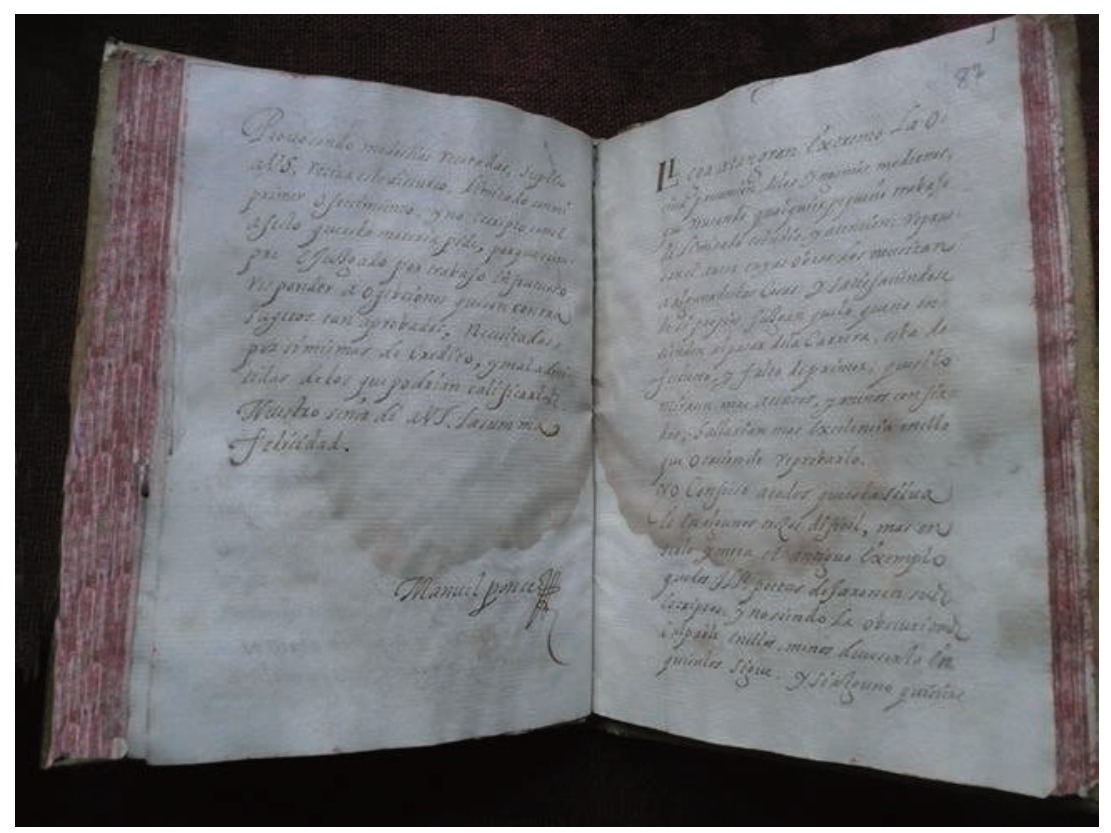

Imagen 7

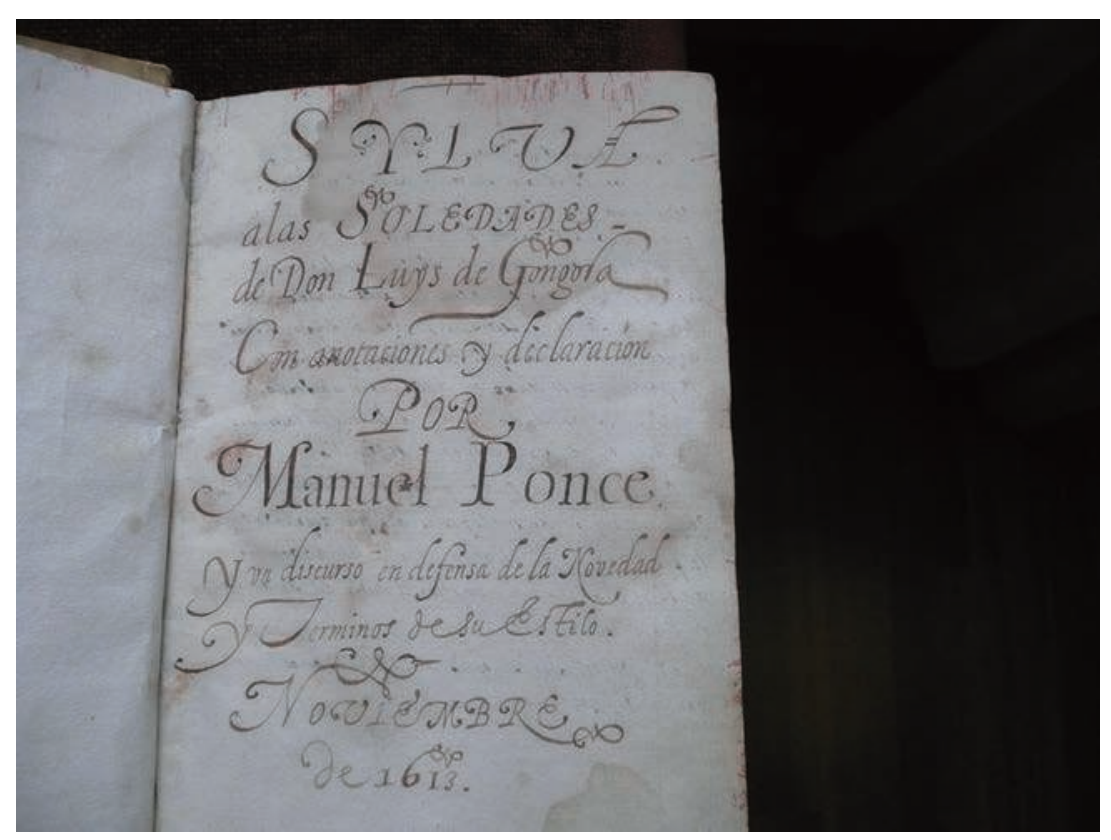

Imagen 8

Sylva a las Soledades de Don Luys de Gongora. Con anotaciones y declaracion por Manuel Ponce, y un Discurso en defensa de la Novedad y Terminos de su estilo. Noviembre de 1613. 
que en esa fecha Ponce tenía ya una idea conjunta de lo que sería el volumen, o bien había finalizado ya la anotación al poema y el discurso en defensa la oscuridad (imagen 8).

No obstante, la crítica ha advertido la aparente contradicción de esa fecha con el hecho de que la versión de la Soledad primera que copia esté cercana a la definitiva, y con que al final incluya el texto de la Soledad segunda desde el verso 677 al verso 936. Por señalar dos posturas al respecto (véanse más en la nota 5), Joaquín Roses (1994: 20-22) acepta la fecha de 1613 y cree que para entonces la versión casi definitiva de la Soledad primera ya estaría bastante difundida. Robert Jammes (1994: 616-618) no descarta que la fecha de la portada sea la del comienzo del trabajo de Ponce que, como ya indicara Dámaso Alonso (1982: 524), se habría continuado posteriormente; sin embargo, también señala que el nombre de Ponce estaba ya en las Advertencias de Almansa ${ }^{19}$, por lo que concluye que «se puede por consiguiente admitir que, de momento, es el primer comentario conocido».

El examen del manuscrito permite añadir otras consideraciones sobre la fecha. No obstante, su delimitación precisa -si ello es posible- exigiría un completo análisis codicológico del volumen manuscrito, y un exhaustivo examen de las fases de redacción de la Soledad primera y la Soledad segunda, cotejándolas con los textos que de ambas ofrece el manuscrito de Ponce. Esta tarea excede el propósito de este trabajo -centrado en las ideas retóricas de Ponce- y deberá ser abordada más adelante.

Volviendo al manuscrito, ya se ha visto cómo grafías, foliación, probable composición de cuadernos y notas marginales apuntan a un trabajo elaborado en varias fases. A ello debe añadirse que, al final de la dedicatoria al conde de Salinas que precede a la anotación (f. 39v), Ponce le promete otro discurso donde responderá a las objeciones contra el estilo de las Soledades. La promesa de ese otro discurso indica, en efecto, que estas dos partes del trabajo de Ponce -anotación del poema y Discurso en defensa de la oscuridad- fueron elaboradas en diferentes momentos.

El final de esa tarea puede ser noviembre de 1613, como se lee en la portada o, si se cree que la fecha de esta se refiere al inicio del trabajo, no podría ir más allá de 1616. Las dedicatorias al conde de Salinas lo mencionan como «Presidente del Consejo Supremo de Portugal», cargo que desempeñó entre 1605 y 1616, para pasar a ser Virrey desde 1617 a $1621^{20}$. Creo que ese término, aunque

19. Para Jammes (1994: 196-198 y 609-611) y Roses (1994: 19-20) fueron redactadas en la segunda mitad de 1613; para López Bueno (2012a: 5 y 18-25) en el verano de 1614.

20. El conde de Salinas ocupó interinamente la presidencia del Consejo de Portugal en 1605 durante la enfermedad de don Juan de Borja, conde de Ficalho, y definitivamente desde su muerte en septiembre de 1606. Fue presidente del Consejo de Portugal de 1605 a 1616, y Virrey del reino de Portugal desde marzo de 1617 a 1621 . Aunque no ocupó efectivamente el cargo de virrey hasta la primavera de 1617, ya en la segunda mitad de 1615 y durante 1616 se hablaba del nombramiento como algo seguro; Dadson, 2011, pp. 97-112 detalla diversos pormenores de este complejo proceso. Más datos en Gaillard (1983); Dadson (1986: 6-7); Dadson (2008: 86); Dadson (2011: 79-116, 138). Las investigaciones que Trevor Dadson lleva a 
prudente, resulta algo exagerado en relación con las tempranas menciones a Ponce entre los conocedores de los poemas de Góngora.

A todo ello hay que ańadir algo obvio: que Ponce no podría haber comenzado su comentario sin tener el texto de la Soledad primera. Si este es el primer requisito, ese texto estaría disponible ya en noviembre de 1613. Si observamos el verso 6 («en dehesas azules pace estrellas»), vemos que la versión recogida en la copia de Ponce es posterior a la primitiva que manejó Almansa y Mendoza («zafiros pisa, si no pace estrellas») en sus Advertencias, escritas en la segunda mitad de 1613 , o en el verano de $1614^{21}$. Se trata de una versión intermedia que manejaron comentaristas como Jáuregui en su Antídoto (1614-1615, según Rico García 2002: XXII), pues aparecía la voz dehesas en una de las listas de términos censurados por Jáuregui (Rico García 2002: 53). A expensas de un examen detallado de todo el texto de la Soledad primera que recoge este manuscrito de Ponce, esa versión del poema, posterior a la manejada por Almansa, estaría finalizada en noviembre de $1613^{22}$.

En conclusión, Manuel Ponce concibió una labor de anotación de la Soledad primera y la elaboración de un Discurso en defensa de su oscuridad. En noviembre de 1613 disponía de una versión del texto posterior a la primitiva y cercana a la definitiva, y sobre ella su trabajo debió de conocer al menos dos grandes fases: la anotación y la posterior elaboración del discurso. Así lo muestran la promesa de este discurso en la dedicatoria que precede a la anotación, y la inicial foliación independiente de ambas secciones. También el hecho de que todas las secciones del volumen comiencen en el recto de un folio y, en algún caso, dejando incluso el vuelto del anterior en blanco ${ }^{23}$. Esa tarea -anotación y Discurso- habría sido concluida en noviembre de 1613, si damos crédito al texto de la cuidada portada y al detalle de Ponce en fechar sus escritos, o, como más tarde, en 1616, cuando el conde de Salinas dejó de ser Presidente del Consejo Supremo de Portugal, aunque cabe pensar que hubiese

cabo con el epistolario del conde de Salinas acaso puedan revelar datos de interés en relación con la dedicatoria de Ponce. Sobre las relaciones entre el conde de Salinas y Góngora, véase Dadson (2014).

21. Véase la nota 19.

22. Además, en ese verso 6 , el revisor del trabajo de Ponce añadió una enmienda en el margen izquierdo que recogía el texto de la versión definitiva («en campos de zafiro pace estrellas»). Ello afectó también al v. 711, donde el revisor incorporó también el texto de la versión definitiva, que, para no repetir la expresión, pasó de «oro mordiendo, campos de zafiro» a «mordiendo oro el eclíptico zafiro». No parece que esas enmiendas del revisor puedan ser muy posteriores a la finalización de la tarea de Ponce que, como fecha más tardía, sería 1616 a la luz de las dedicatorias al conde de Salinas. En otros versos donde Almansa recoge la lectura primitiva, el texto de Ponce coincide con la versión final: así sucede en los vv. 75, 100, 375, 416 y 473 . En el verso 206, la versión de Ponce también coincide con la definitiva, y no recoge los versos que Almansa comenta: «de islas que paréntesis frondosos / al período son de su corriente». Tampoco recoge los vv. 290-294: «treinta robustos montaraces dueños / en la tierna hijuela temer vieras / ya en la vaca, no en las empulgueras / del arco de Diana / damería serrana».

23. Un más detenido examen del volumen, que espero realizar para la futura edición, permitirá confirmar si se produce también un cambio de cuaderno, algo que parece advertirse ya en algunos casos al revisar las imágenes. 
finalizado antes de esa fecha a la luz del devenir de la polémica gongorina. Posterior a la anotación es la tarea del revisor que corrige algunos versos de la Soledad primera con la lectura definitiva y enmienda notas de Ponce, así como las réplicas de Ponce a algunas de sus observaciones.

Probablemente el final de esta tarea escalonada que recoge el volumen manuscrito venga dado por el pasaje de la Soledad segunda que se copia en los últimos folios, y que abarca desde el verso 677 («Las Horas ya, de números vestidas») hasta el verso 936 («heredado en el último graznido»). Este pasaje intenta reproducir de manera no fragmentada el episodio de la caza de cetrería ${ }^{24}$. Su título en el manuscrito también parece indicarlo así: «Segunda Soledad / El periodo de la caza». Este texto, que ocupa los folios 113r-120v, fue copiado por Manuel Ponce y no por quien copió los versos de la Soledad primera en la parte inicial del manuscrito. Además, el texto comienza -como sucede en las diversas secciones del manuscrito- en el recto de un folio, y parece que inicia también un cuaderno, rasgos todos ellos que confirman las sucesivas fases de elaboración de los materiales y tareas que configuran el manuscrito ${ }^{25}$.

En cuanto a la fecha de esta parte final que recoge los versos de la Soledad segunda, si aceptamos la hipótesis cronológica dada por Jammes (1994: 19), esa versión del poema sería posterior (¿poco posterior?) a 1617, pues la edición de Vicuńa, que se supone conocía la parte del poema redactada hasta 1617, finaliza en el verso 840 («al viento esgrimirán cuchillo vago»). El trabajo donde Mercedes Blanco muestra las semejanzas entre este episodio de la Soledad segunda y un pasaje del sermón de Paravicino para las fiestas de Lerma en octubre de 1617 invita a pensar en una fecha algo anterior, pues implicaría que esta parte de la Soledad segunda estaba ya compuesta en ese año ${ }^{26}$. Como se ha señalado, el cotejo detenido de las versiones del poema permitirá determinar con mayor exactitud estas cuestiones que aquí solo se apuntan.

A continuación me centraré en los planteamientos retóricos de Ponce que pueden observarse en las diferentes secciones: notas, dedicatorias y Discurso.

Las 104 notas que Ponce añade al texto de la Soledad Primera no abundan en explicaciones retóricas. Como es habitual en este tipo de anotaciones, suelen dedicarse a explicar las alusiones mitológicas y diversas informaciones referentes a animales o geografía ${ }^{27}$. En este sentido, Dámaso Alonso (1982: 515) advirtió que Ponce "era un especialista en noticias sobre el Nilo", pues la extensión de su nota 101, referida a ese río, era mucho mayor que la de las

24. Algo que sucedía en la edición de Vicuña, que recoge el texto hasta el v. 840 («al viento esquivarán cuchillo vago»). Véase Jammes (1994: 19).

25. Osuna Cabezas (2008: 114-115) propuso como hipótesis de trabajo que el comentario comenzó a escribirse en noviembre de 1613 y, una vez concluido, se le añadieron tiempo después los versos de la Soledad segunda.

26. Véase Blanco (2012: 58-62).

27. Ejemplos de ello son la nota 29 referente al pez rémora (f. 49v), o la 37 sobre el pavo venido de América (ff. 51r-52r); en cuanto a la geografía, la nota 33 sobre el río Termodonte (ff. 50r-50v). 
restantes (ff. 77r-82r, y más informaciones en apéndice en el f. 84r). Una vez conocido el texto de la Apología en defensa de Virgilio no extraña ese rasgo, pues en los versos de la cuarta Geórgica objeto de discusión (vv. 287-294), Virgilio hablaba de las tierras del Nilo a propósito de la producción de miel. Ponce debió de aprovechar materiales que estaba consultando para la elaboración de ese comentario a Virgilio (fechado en 1622) y los aplicó para enriquecer en erudición esta nota al verso de Góngora. En este sentido, además de las noticias sobre el Nilo que incorpora en la anotación, Manuel Ponce recogió en un folio (f. 84r) una lista de autores que ofrecían noticias sobre el Nilo diferentes de los que él señalaba en la nota al poema de Góngora.

Más cercanas a la retórica están las numerosas notas en las que Ponce explica el sentido de metáforas, perífrasis o voces de difícil comprensión, o parafrasea versos reordenando su compleja sintaxis. En este tipo de notas, Ponce no se detiene en consideraciones teóricas sobre los tropos y figuras empleados. Solo en cinco ocasiones la nota de Ponce hace alguna precisión retórica, aunque tampoco extensa, pues no es la anotación el lugar adecuado para dichas cuestiones. Se limita en ellas a señalar el nombre de la figura o tropo en cuestión: metonimia en la nota 10 (f. 43v) al verso «que a Vulcano tenían coronado» (v. 93), hipérbole en la nota 66 (ff. 64r-64v), que corresponde a los versos 550-555, e ironía compuesta en la nota 39 (ff. 52r-52v), donde Ponce explica el sentido de los versos 329-334 ${ }^{28}$ y añade la siguiente precisión retórica: «Este concepto es ironía compuesta en que dice que resistía el gamo ser llevado a los novios, porque el matrimonio aborrece hasta la sombra del cuerno». En efecto, la ironía que encierra el pasaje es compuesta, pues no afecta a una sola palabra, sino al conjunto de los versos, y se halla en el agudo doble sentido que interpreta, detrás del joven gamo ofrecido como regalo de bodas, una burlesca alusión a los cuernos del matrimonio.

Otras dos notas donde Ponce se demora algo más en consideraciones retóricas afectan a las que, en general, podríamos englobar bajo el rótulo de verba peregrina, es decir, voces nuevas y de otra lengua ${ }^{29}$. Es un aspecto que preocupó mucho a Ponce, quien le volverá a dedicar una amplia sección de su Discurso en defensa de la oscuridad, y que centrará, en torno a 1617, su Epistola a Villamediana. El abuso de este tipo de voces era una de las objeciones principales planteadas al poema de Góngora, pues sus detractores argumentaban que, desde la preceptiva retórica, atentaba contra la propiedad del lenguaje.

28. Sobre las críticas a esta agudeza por parte de los detractores de Góngora, véase Jammes (1994: 266-268).

29. Aristóteles maneja el concepto de verba peregrina en un sentido amplio que parece abarcar todo vocablo fuera del uso común: «y entiendo por voz peregrina la palabra extrańa, la metáfora, el alargamiento y todo lo que se aparta de lo usual» (Poética, 1458a 22-24). No obstante, su acepción más habitual (que por ejemplo seguirá Quevedo) es la de 'voces de otra lengua'. Acumular excesivas voces foráneas se consideraba ya en las preceptivas antiguas una transgresión de la proprietas («ajeno de lo propio», traduce Quevedo en los preliminares literarios a su edición de fray Luis, p. 41, f. 3). Véase Azaustre (2003: 70). La norma se aplicará al estilo culto y sus frecuentes latinismos. Ver las opiniones que recoge Roses Lozano (1994: 153-168) en torno a la recepción de las Soledades. 
Esta censura debe entenderse teniendo en cuenta que, en la retórica romana, la proprietas se cifraba a menudo en la latinitas de la lengua, lo que exigía moderación en el uso de voces foráneas y neologismos ${ }^{30}$.

La primera de esas notas (nota 27, f. 49r) justifica el uso del cultismo venatorio en el verso 230 («al venatorio estruendo»). Para ello, Ponce se apoya en los vv. 52-53 del Arte Poética de Horacio, un conocido pasaje donde se justifica el uso de nuevas voces si proceden de términos griegos ${ }^{31}$; el razonamiento de Ponce -reiterado en la polémica gongorina-considera que, igual que era lícito al romano introducir voces nuevas apoyándose en el griego, lo mismo sucederá al poeta romance si las suyas derivan del latín: «La voz venatorio es latina, y traída según el precepto de Oratio. Si graeco fonte cadant» (f. 49r).

La segunda nota (nota 68, ff. 64v-65r) utiliza los mismos argumentos para justificar el uso del término meta en el verso 581 («meta umbrosa al vaquero convecino»). Ponce ańade ejemplos latinos e italianos que ya la emplearon, a los que une la autoridad de Garcilaso, muy del gusto de los defensores de Góngora porque, como es sabido, además de probar que el poeta cordobés no era el primero en practicar esos usos en castellano, dicha prueba se hacía con un autor emblema de la claridad en el estilo (en todas las citas, el texto entre corchetes es mío): «Meta es voz latina y toscana que significa en ambas lenguas el término de el camino, como he dicho. Virg. 1. 5. Hic viridem Aeneas frondenti ex ilice metam / constituit [vv. 129-30]. Sannazaro. Ove qualunque chi per velocità primo / la destinata meta toccava [prosa 5]. Y usar desta voz en nuestra lengua no debe ser culpable en nuestro autor, no siendo él el primero que lo ha hecho, pues Garcilaso en la elegía al duque de Alba, en el 11 terceto, después del numº 59 dijo "cuando voló el espíritu a la alta meta"».

El texto de la Soledad primera y la sección de notas van precedidas de dos dedicatorias: la primera de ellas "A los que no entienden esta silva» (ff. 2r3r), y la segunda "Al conde de Salinas, presidente del Consejo de Portugal» (ff. 34r-40r).

La dedicatoria "A los que no entienden esta silva" constituye una breve justificación de la anotación al poema de Góngora, al tiempo que una censura dirigida a quienes criticaban su oscuridad. Es precisamente esa oscuridad la que justifica el esfuerzo de Ponce en anotar los versos. El comentarista cifra las críticas a esa oscuridad en tres razones que, al mismo tiempo, están apuntando a tres tipos de ingenios incapaces de comprender el texto:

1) «por la continuación de metáforas, hipérboles, translaciones, metonimias, repeticiones, exclamaciones, símiles, descripciones, transgresiones y locuciones [es oscura] a los que carecen de los preceptos de la retórica y poética» (f. 2 r).

2) "por la gramática, términos y frases nuevas [es oscura] a los que carecen de las lenguas latina y toscana a quien imita su autor en el estilo, gravedad y heroicia» (ff. 2r-2v).

30. Véanse, por ejemplo, Cicerón, De Oratore, 3, 11, 40 y 3, 13, 49; Cicerón, Brutus, 132, 261; Rhetorica ad Herennium, 4, 12, 17.

31. «et nova fictaque nuper habebunt verba fidem, si / Graeco fonte cadent parce detorta». 
3) "por las imitaciones, historias y fábulas y antigüedades que tiene es dificultosa a los que carecen de la lección de letras humanas y noticia de los poetas e historiadores» (f. $2 \mathrm{v}$ ).

Las razones esgrimidas por Ponce sintetizan las principales vertientes de la censura a las Soledades: excesos en el ornatus y verba peregrina, y complejidad en los contenidos y alusiones históricas, literarias y mitológicas. Esto es, los dos grandes tipos de oscuridad recogidos en la preceptiva literaria: la proveniente de la forma -habitual blanco de censuras- y la que derivaba de la complejidad o misterio de los asuntos, admitida - cuando no alabada- como signo de erudición o trascendencia del poeta ${ }^{32}$.

La dedicatoria que precede a la anotación (ff. 34r-40r), dirigida al Conde de Salinas, es una amplificación de la anterior. Su organización sigue un esquema retórico que comienza por un breve exordio, continúa con el grueso de la exposición (narratio y argumentatio) y remata con una breve conclusión.

El exordio reúne la tópica captatio benevolentiae del destinatario, el conde de Salinas, a quien se alaba especialmente por su talento artístico y sensibilidad favorable al poema de Góngora, lo que explica que Ponce le dedique el escrito y lo someta a su juicio. Aparte de ello, la humilitas autorial se combina con la ponderación de la dificultad del poema, tan alta que a menudo hizo a Ponce desistir de su intento de comentarlo. Esta habitual estrategia de los exordios es muy del gusto de Ponce, quien también la empleó en el comentario de Virgilio que dirigió a Pedro de Torres Rámila:

Mil veces he resistido el animoso intento de imbestigar la inteligencia desta silua; viendo que tantos sugetos ingeniosos la deponen y se priuan de entenderla. Y otras tantas me a vencido la porfía de vn secreto impulso, quiçá mouido (con arduas esperanzas) de la misma dificultad desta ympresa; cuyo onor (si vien desconfío merecerle) deuía ser ygual al riesgo que tiene el echo; mas ya que prometí su cumplimiento al deseo forzoso a de ser que le tenga, quedando en obligazión (no pequeńa) a mi yngenio, con quien e querido adeudarme, reconociendo el crédito grangeo en intentar lo que tantos an temido (Sylva a las Soledades, ff. 34r-34v)

Y mándame decir mi sentimiento, juzgando que la sufiçiencia que me atribuie su favor podrá haçer el efecto que si fueran iguales sus quilates en mi talento a los que me concede su confiança. Pueda en mí su preçepto lo que no consiguiera mi cuidado, aun persuadido de tener algún premio en la inteligençia de lugar tan difícil. Y pues lo sagrado de sus atençiones no debe inclinar los ojos a las humanas tinieblas, permítase a los desbelos humanistas, si no a la diciplina de la crítica enseñança, la exposiçión de lugar que tantos an juzgado inaccesible, atribuyendo la culpa de corta diligencia al superior ingenio de el autor (Apología en defensa de Virgilio, f. 132r)

Ponce califica a los detractores de Góngora como «el torrente de los doctos, agudos y curiosos, de cuyas tres especies no e visto que alguno aya aprobado en todo esta silva» (f. 34r). Esa clasificación va a ir vertebrando la parte central de la dedicatoria, donde Ponce adjudica a cada uno de ellos las censuras que

32. Sobre el fenómeno de la oscuridad en el ámbito de esta polémica, véase Roses Lozano (1994: 66-151). 
atribuyen al poema. En la primera dedicatoria, «A los que no entienden esta silva» (ff. 2r-3r), Ponce también los había organizado en tres grandes categorías ${ }^{33}$.

La primera causa formulada por los doctos reúne dos aspectos que, según la preceptiva retórica, provocarían la excesiva oscuridad de la expresión: la frecuencia de voces nuevas y foráneas y de translaciones remotas, es decir, de tropos donde la analogía se advierte con gran dificultad. Esa censura se apoyaba en un conocido pasaje de la Poética de Aristóteles:

Porque la obscuridad de la oración nace de valerse el poeta de voces nuebas y no usadas, y continuada frecuencia de translaciones remotas, de cuya unión resulta este incombiniente, según el precepto de Aristóteles, cuyas palabras son estas:

Nerum si quis simul omnia huiuscemodi fecerit, vel aenigma erit, vel barbarismus, si quidem igitur e translationibus, aenigma: si autem e linguis, et barbarismus (Ponce, Sylva ff. $35 \mathrm{r}-35 \mathrm{v})$

Es este un pasaje de la Poética de Aristóteles que se citará bastante en estas polémicas; por ejemplo, en el Discurso poético (p. 126) de Jáuregui, o en el Parecer de Francisco Fernández de Córdoba (pp. 133 y 135). Quevedo también lo mencionará en los preliminares literarios a su edición de la poesía de fray Luis de León, o en su Comento contra setenta y tres estancias que don Juan Ruiz de Alarcón ha escrito... (p. 398b). La temprana mención de Ponce lo sitúa ya al comienzo de la polémica.

No es extraño que quienes recurrieron a la máxima autoridad de Aristóteles hubiesen citado este pasaje. En esta sección de su Poética (1458a18-1459a16), Aristóteles contemplaba diversos recursos que producen una dicción excelente: voces peregrinas, alargamiento, apócope o alteración de vocablos, metáfora... En todos ellos consideraba conveniente la moderación que lograse un equilibrio entre la grosera escasez de adorno lingüístico y la oscuridad de su exceso. Esta tan citada sección de la Poética se mueve, pues, en esa línea de recomendaciones teóricas sobre moderación y buen uso que tanto propiciaron comentarios e interpretaciones divergentes a la hora de contrastarlas con la práctica literaria. Esta posición intermedia dará pie a que los defensores del estilo culto citasen como autoridad los pasajes donde Aristóteles alababa las voces peregrinas y las metáforas, y los detractores aquellos donde censuraba el abuso de ellas. Ponce reproduce aquí esta parte pues está recogiendo las censuras al poema que atribuye a los doctos ${ }^{34}$.

33. Juan Manuel Daza (2014b) considera que estos destinatarios no implican necesariamente censuras reales al poema de Góngora, y propone que entre 1613 y 1615 existió una estrategia gongorina de «defensa preventiva» de la Soledad primera, adelantándose a las objeciones que sin duda habría de despertar el poema. El texto de Ponce-como las Advertencias de Almansa-serían parte de esa estrategia programática.

34. Este comportamiento es común a otros tratadistas de poética y retórica, pues la moderación estilística es una recomendación general de las preceptivas. El propósito didáctico de las preceptivas explica en parte esa norma de equilibrio y moderación, pues la prudencia es una recomendación de amplio alcance y asimilación entre los más diversos destinatarios. Además de ello, ya desde Aristóteles (Ética a Nicómaco, libro 2, capítulo 6) se había fijado en el justo 
La segunda censura de los doctos (f. 35v) se refiere a otro de los pilares de la interpretación y juicio de las Soledades: el género del poema y la adecuación a su estilo ${ }^{35}$. Los doctos seńalan que el estilo del poema no guarda el decoro con respecto al asunto que trata $-\mathrm{y}$, en consecuencia, al género, vinculado a este-, pues se eleva impropiamente a lo heroico cuando el asunto lírico del poema requeriría otro registro ${ }^{36}$.

Una nueva crítica de los doctos (ff. 35v-36v) se centra en el uso de voces ininteligibles por nuevas o foráneas, lo que atenta contra la claridad y la puritas del lenguaje. Es un aspecto que, como hemos visto, centra mucho la atención de Ponce. Dos citas de Quintiliano acompañan esta crítica: la primera (Institutio Oratoria $1,5,71)$ donde habla de los riesgos de acuñar voces nuevas ${ }^{37}$; la segunda (Institutio Oratoria 1, 6, 41) donde se indica que el discurso que necesita intérprete resulta vicioso, pues la primera virtud ha de ser la claridad ${ }^{38}$. A ellas se une un pasaje de Cicerón (De Officiis 1,111) sobre la conveniencia de usar la lengua propia y no introducir constantemente voces extranjeras ${ }^{39}$.

Aunque formulada de manera muy breve, puede advertirse en las siguiente frase una censura de los doctos contra la falta de profundidad en los contenidos de las Soledades, aspecto que iría íntimamente conectado con el de la oscuridad pues, como se ha dicho, las preceptivas admitían la oscuridad derivada del misterio o complejidad de los asuntos tratados ${ }^{40}$ : «y [hallan los doctos] que los conceptos son pocos, y menos las sentencias que son parte necesaria en el poeta» (f. 36v). Esta línea de censura será muy destacada en autores como Jáuregui o Lope, para quienes el poema de Góngora carecía de la profundidad que justificase su complejo estilo.

medio la naturaleza de toda virtud. La moderación entre los extremos se concreta a menudo en formulaciones que recomiendan el uso del rasgo de estilo y señalan sus virtudes, para luego advertir sobre sus peligros. Ello provoca la fácil e interesada segmentación de los pasajes, como sucede en este caso. Sobre esta cuestión, véase Azaustre (2005 y 2013).

35. Véase Roses Lozano (1994: 121-141).

36. Como en todos los casos, la censura se acompaña de una autoridad que se presume habrían aducido como refuerzo los detractores de Góngora; en este caso, los versos 89-91 del Arte Poética de Horacio: «Versibus exponi tragicis res comica non vult / indignatur item priuatis ac prope socco / dignis carminibus narrare cena Thyestae». El pasaje también fue usado por un defensor del poema gongorino, el autor de la Soledad primera, ilustrada y defendida (véase Osuna Cabezas, 2009: 384), para rebatir a Jáuregui su censura hacia el empleo de voces del campo; Horacio sirve aquí como autoridad que avala el decoro que Góngora respeta al tratar asuntos pastoriles. Es una muestra más del frecuente uso argumentativo de las autoridades que se llevó a cabo en esta polémica; véase Pérez Lasheras (2009: 78-79); otros ejemplos en Azaustre (2005).

37. «Propria sunt uerba, cum id significant, in quod primo denominata sunt, tralata, cum alium natura intellectum, alium loco praebent. Vsitatis tutius utimur, noua non sine quodam periculo fingimus» (Quintiliano, Institutio Oratoria, 1, 5, 71).

38. «Oratio uero, cuius summa uirtus est perspicuitas, quam sit uitiosa, si egeat interprete!» (Quintiliano, Institutio Oratoria, 1, 6, 41).

39. "Vt enim sermone eo debemus uti qui notus est nobis, ne ut quidam graeca verba inculcantes iure optimo rideamur» (Cicerón, De Officiis, 1, 111).

40. Roses Lozano (1994: 102-111). 
El último aspecto censurado por los doctos es el de la mala imitación de los modelos (ff. 36v-37r), «desuiándose con extremo de los términos en que escriuieron todos, porque en los griegos, toscanos y los demás bulgares no hallan conformidad con lo que él escriue» (f. 36v). Esta idea se amplifica indicando que en ninguna época se vio que un poeta vivo no fuese comprendido de los que tenían su mismo idioma (ff. 36v-37r).

Ponce enlaza así con las críticas que los agudos -a los que ahora llama «ingeniosos»- y los curiosos lanzan contra el poema del cordobés. Si en los doctos las censuras se basaban en la ignorancia de la poética y la retórica, en agudos y curiosos se fundamentarán en calificar como error del poema lo que en realidad es falta de lecturas y conocimientos:

y a esta causa los que se solicitan opinión de ingeniosos, allándose perdidos en esta nauegación, reprueban lo que no entienden, atribuyendo su defecto a lo escripto, y no a lo poco leydo (Ponce, Sylva, f. 37r)

y los curiosos (que exceden en número a los referidos [los agudos o ingeniosos]), desesperados de descubrir su curiosidad, tratando con la deuida noticia deste admirable papel, se disculpan del mismo modo diciendo que no es cosa digna de que los hombres de buen juicio se ocupen en ella; no mirando que por su misma sentencia quedan obligados a estudiarle (Ponce, Sylva, f. 37v)

Entre esos defectos que intentan encubrir su ignorancia, los agudos aducen la falta de adecuación entre género y estilo, aspecto que ya se mencionó al reproducir las críticas de los doctos. Para estos censores agudos, el estilo de las Soledades pretende una gravedad heroica que no se adecua a su carácter lírico:

y dicen que carece del natural lenguage y propiedad de los términos, pues en los que está escripto no se halla igualdad heroica ni dulzura lírica ${ }^{41}$, sino graues acometimientos y realces violentados que desfallecen donde más deuían sustentarse; y que en el Polyphemo y en esta silua a errado los estilos, porque en aquél, que contenía una acción lírica, no escriuió lírico, y en esta, que también lo es, a escripto versos cuyo nerbio es heroico (Ponce, Sylva, ff. 37r-37v)

Hasta aquí la parte central de la dedicatoria, donde Ponce se ha limitado a enumerar un torrente de censuras que acosaban al poema de Góngora, sin dedicarse a rebatirlas, algo que reservará para el Discurso en defensa de la oscuridad.

El final de la dedicatoria se centra en alabar con vehemencia el arte de Góngora y censurar con la misma intensidad la ignorancia de quienes lo critican. La enumeración de sus virtudes suma a lo ornamentado del estilo y los pensamientos sutiles la propia novedad del poema en nuestras letras, que

41. Se refiere a los sonidos blandos que requiere el verso lírico y a la igualdad de la cadencia que exigía el heroico. Véase el siguiente pasaje de Almansa: «si heroicos, llenar de voces graves el verso en la igualdad de su cadencia, y si líricos, de voces blandas» (Advertencias, pp. 32-33). Las semejanzas entre los textos de Almansa y Ponce ya fueron advertidas por Dámaso Alonso (1982: 523); Osuna Cabezas (2008: 113-114, 117, 124); López Bueno (2011: 244, 252); López Bueno (2012a: 22) y Daza (2014b). 
para Ponce es motivo de admiración y alabanza. Esa singularidad de su poema eleva el castellano «a la cumbre de la grauedad y número latino» (f. 38r) y a «la veruosidad, cadencia y suabidad de los toscanos, que oy tienen el lugar segundo en estas letras» (f. 38v).

La censura a los detractores se fundamenta en su ignorancia, y se plasma con rotundidad en el siguiente dilemma, muy semejante a un pasaje de las Advertencias de Almansa ${ }^{42}$ :

Si lo entienden, no oscuros; si no lo entienden, no lo juzguen (Almansa, Advertencias, p. 200)

y querría preguntarlos, si no le entienden vien, ¿por qué le enmiendan? y si le entienden, ¿por qué le culpan de obscuro? (Ponce, Sylva, ff. 38v-39r).

Esta dedicatoria se cierra con una peroratio (f. 39r-40r) donde Ponce lamenta la envidia y falta de reconocimiento del talento ajeno en su tiempo (f. 39r-39v). A ello le sigue la preceptiva alabanza final del conde de Salinas y la promesa de enviarle un discurso donde responderá a esas objeciones contra el estilo de las Soledades. La dedicatoria concluye -hay que reconocer que de forma práctica pero poco solemne- con una breve explicación del sistema de notas que se seguirá a continuación.

La promesa efectuada al conde de Salinas se cumple en el Discurso que se copia al final del manuscrito (ff. 85-108v). Su prolijo título -rasgo común a otros escritos de Ponce- muestra a las claras su objetivo: la defensa de la oscuridad como rasgo esencial en la poesía:

Discurso en que se trata si en los términos de la Poesía es necesaria la obscuridad y forzosa en las locuciones della. Y en qué modo se puede permitir que el Poeta sea obscuro a los ignorantes de los preceptos del Arte; y facultades que se cifran en los versos. Y si el que a todos es difícil se ha de reprobar y no estudiarle. (Ponce, Discurso, f. $85 \mathrm{r}$ )

El examen del texto completo confirma las opiniones que la crítica ya había manifestado a la luz de los pasajes dados a conocer por Dámaso Alonso. El Discurso de Ponce es una defensa de Góngora basada no en negar la oscuridad de su poema, sino precisamente en considerarla rasgo esencial del mismo y, más allá, principio vertebrador de la poesía ${ }^{43}$.

El Discurso comienza con una nueva dedicatoria al conde de Salinas donde Ponce, además de cumplir con la preceptiva captatio benevolentiae, afirma

42. Véase la nota anterior para las semejanzas entre los textos de Almansa y Ponce.

43. Roses Lozano (1994: 86-91) destaca que en este temprano comentario se observa una profunda y bien razonada defensa de la oscuridad de Góngora, no una mecánica negación de la misma. Antes había afirmado que «la mayoría de los defensores del poeta rechazaban tajantemente las acusaciones de oscuridad vertidas sobre el nuevo estilo» (Roses Lozano, 1994: 81). Osuna Cabezas (2008: 141) señala que Ponce justificó la dificultad de Góngora por el elitismo de la poesía. Véanse también las observaciones de López Bueno (2011: 244), López Bueno (2012a: 22-24) y Daza (2014b), quienes lo incluyen en una corriente temprana de defensas programáticas surgidas en un círculo muy próximo a Góngora. 
cumplir la promesa de enviarle una defensa del poema gongorino frente a las múltiples críticas que dice haber suscitado, y que atribuye a la ignorancia y escaso ingenio de sus detractores (ff. 86r-86v) ${ }^{44}$. Ponce critica la ociosidad de los ingenios, que, tras una rápida lectura, prefieren censurar aquello que no entienden antes que dedicarle estudio y atención (f. 87r). Es una afirmación que ha repetido en las anteriores dedicatorias y que sirve también para subrayar su valor y esfuerzo como comentarista.

Ponce admite la oscuridad del poema de Góngora, pero la justifica con el antecedente de los poetas y filósofos antiguos y con las Sagradas Escrituras, apoyándose además en el dictamen de Boccaccio (Genealogia deorum gentilium libro 14, cap. 12, «Damnanda non est obscuritas poetarum»). Pero no se trata de una simple acumulación de autoridades que avalan el estilo de Góngora, sino de la manifestación de la esencia superior de la poesía que, como los textos filosóficos y religiosos, encubre bajo una forma sublime contenidos misteriosos y trascendentes; más aún, si la realidad que trata no es compleja, habrá de sublimarla mediante la dificultad de la expresión poética:

No pues será la obscuridad culpable en los poetas, imitadores en ella de la escriptura
diuina y de los Philósofos grabes. Y deue considerarse que el oficio del poeta no es
descubrir las cosas que de por sí están cubiertas con algún velo, antes si son claras y
manifiestas, cifrarlas con quanta diligencia y estudio pudiere, y encubrirlas a los ojos
de la ignorancia porque la demasiada familiaridad no las deslustre, antes sean por su
dificultad más dignas de memoria y reberencia (Ponce, Discurso, ff. $89 \mathrm{r}-89 \mathrm{v}$ ).

Este rango especial del poeta, que entronca con las teorías sobre su origen divino y las defensas del elitismo y el furor poético, será la base que vertebre todo su discurso. Vinculada al elitismo de la poesía está la afirmación (f. $89 \mathrm{v}$ ) de que Góngora no oscureció su poema por capricho erudito o para negar la comprensión de su sentido, sino para que este se valorase más al fatigar el entendimiento en su lectura, diferenciando así los que Ponce califica de «ingenios valientes» frente a los «inferiores».

Esa línea de argumentación continúa cuando se defiende la oscuridad como rasgo esencial del poeta recurriendo al étimo de poeta y poesía, en una defensa que coincide con la que aparece en un conocido pasaje de la Carta en respuesta... atribuida a Góngora y las Advertencias de Almansa ${ }^{45}$ :

44. Como se ha indicado, para Daza (2014b), podría tratarse no de una defensa frente a críticas reales, sino, sobre todo, de una defensa previa y preventiva como parte de un programa organizado en círculos cercanos a Góngora.

45. Para las semejanzas entre los textos de Almansa y Ponce, véase la nota 41. Las semejanzas entre la Carta en respuesta... y las Advertencias de Almansa también han sido advertidas por la crítica; véanse Carreira (1998: 263-264); López Bueno (2012a: 22-23) y Daza (2014b). La carta habría sido escrita el 30 de septiembre de 1613 para Carreira (1986: 339-341), Carreira (1998: 239-260) y Jammes (1994: 612-616). Para López Bueno (2011), López Bueno (2012a: 5-6), López Bueno (2012b: 206-207) y Daza (2011), su redacción habría tenido lugar el 30 de septiembre de 1615. 
Demás que honra me ha causado hacerme oscuro a los ignorantes, que esa es la distinción de los hombres doctos, hablar de manera que a ellos les parezca griego; pues no se han de dar las piedras preciosas a animales de cerda; y bien dije griego, [porque Poesía es] locución exquisita que viene de Poeses, verbo de aquella lengua madre de las ciencias (Carta en respuesta..., pp. 181-182)

Poaetes antiquísima voz griega que se lee exquissita locución, porque los primeros de ynflamado espíritu comenzaron a hablar diuersamente del común en aquel siglo báruaro, como aora en el verso, que al fin era vna suerte de locución rara y no conocida (Ponce, Discurso, f. 90r)

San Jerónimo en el prólogo de Job, dando la definición de poesía, dijo que venía de Poeses, nombre griego que quiere decir locuciones exquisitas, y si alguna persona con justa causa puede ampliar la lengua es el Sr. Don Luis, que es dueño de ella, porque los valientes atrevimientos se conceden a valientes ingenios (Almansa, Advertencias, p. 199)

A pesar de ser un defensor de la oscuridad, Ponce recurre a dos símiles aclaratorios para explicar su necesidad en la poesía. El primero de ellos (f. 90v) plantea que, así como el conocimiento de las artes más nobles se alcanza con gran dificultad, lo mismo cabe decir de la poesía, que abarca y trata las más realzadas y sublimes materias. El segundo (ff. 91r-91v) señala que, así como para entender las artes y disciplinas superiores es necesario conocer las inferiores -la filosofía para la teología, por ejemplo-, así es necesario un profundo conocimiento de asuntos y oficios para comprender a los poetas sublimes que abarcan gran cantidad de saberes.

Esa manifestación de la superioridad de la poesía se cierra con un lamento (ff. 91v-92r) por haber perdido en tiempos de Ponce la dignidad que tuvo en su origen, cuando fue constituida para deleitar los oídos de los dioses. Ese lamento apunta a Góngora como excepción sublime, y a sus detractores como ingenios miserables que carecen de la altura necesaria para juzgarlo.

El Discurso de Ponce avanza con un razonamiento complementario que resulta de capital importancia en el desarrollo e interpretación de la polémica gongorina: la diferencia entre el poeta y el orador. Al principio Ponce vincula esta diferencia a la consideración sublime de la poesía, pues afirma (f. 92r-92v) que si el poeta no elevase su elocución oscureciéndola, solo se diferenciaría del prosista, el orador y el vulgo por el metro. Pero al ser el poeta sublime representante del furor divino, su elocución no puede ser clara, pues persigue necesariamente la oscuridad propia de ese rango superior.

Más adelante (ff. 95v-96v), Ponce vuelve a este argumento de una manera más concreta cuando refuta a quienes defienden la claridad en poesía apoyándose en Cicerón y Quintiliano. Haciendo gala de una correcta interpretación de los tratados de retórica, Ponce afirma que ellos nunca dieron preceptos a los poetas, sino a los oradores. Muestra así una cabal comprensión de las constantes excepciones que los gramáticos y los rétores hacían con los poetas a la hora de reconocer como licencias poéticas los vicios gramaticales que censuraban, y de recomendar moderación en los diferentes recursos del ornatus, aspecto 
del que me he ocupado en otro lugar y que no siempre fue suficientemente aprovechado por los defensores de Góngora ${ }^{46}$.

Ponce desciende en algunos momentos a la explicación concreta de versos y voces del poema para ilustrar sus preceptos teóricos. Así sucede cuando se centra en las que considera cinco voces extrañas que Góngora usó en su poema (venatorio, conculcado, meta, gulosos, vipartida). Resulta interesante que en la justificación de estas recurra al mismo lugar de la Poética de Aristóteles (1458a18-1459a16) que en la dedicatoria previa a la anotación del poema había señalado como aval de los detractores de Góngora ${ }^{47}$. La explicación, ya comentada, es que allí los críticos se agarraban a la recomendación de mesura estilística del Estagirita ante la posibilidad de caer en el enigma o el barbarismo (Poética 1458a24-26), y aquí Ponce se apoya en el pasaje donde Aristóteles reconoce que los alargamientos, apócopes y alteraciones de vocablos evitan la vulgaridad y contribuyen a la excelencia de la elocución (Poética 1458b1-5):

Nerum si quis simul omnia huiuscemodi fecerit, vel aenigma erit, vel barbarismus, si quidem igitur e translationibus, aenigma, si autem e linguis, et barbarismus (Ponce, Sylva ff. 35r-35v) («Pero si uno lo compone todo de este modo, habrá enigma o barbarismo; si a base de metáforas, enigma; si de palabras extrańas, barbarismo», Aristóteles, Poética, 1458a23-25)

Non populare quidem igitur faciet, et alia dicte formae: propium autem claritudinem. Non minimam autem partem conferunt, ut locutio aperta sit, et non popularis, productiones et ablationes et immutationes nominum. Quia enim hoc aliter se habet quam propium, cum factam sit contra id quod consuetum, reddet in oratione non bulgare genus (Ponce, Discurso, f. 93v) («También contribuyen mucho a la claridad de la elocución y a evitar su vulgaridad los alargamientos, apócopes y alteraciones de vocablos; pues por no ser como el usual, apartándose de lo corriente, evitará la vulgaridad», Aristóteles, Poética 1458b1-4)

Esa pequeña digresión que justifica las voces nuevas introducidas por Góngora se abandona y pospone para más adelante, y Ponce vuelve a justificar la oscuridad del poeta apoyándose de nuevo en Boccaccio (Genealogia deorum gentilium 14, 7, «quid sit poesis, unde dicta, et quod eius offitium»), pasaje en el que se manifiesta de manera palmaria la doctrina del furor poético ${ }^{48}$ :

El Boccacio en el 14 de la Geneal. de los Dioses dice: Los efectos de Poético furor son conducir la mente en el ánimo de decir bien, ymaginar raras y jamás oydas

46. Sobre estas cuestiones, véanse Pérez Lasheras (2009: 78-92), Daza (2010 y 2014a) y Azaustre (2013). Aunque anterior a esta polémica, debe recordarse la importancia que este punto de vista tiene en el Libro de la erudición poética de Luis Carrillo y Sotomayor.

47. El pasaje se encuentra en la sección 22, p. 210 de la edición trilingüe de García Yebra recogida en la bibliografía, y por la que cito las traducciones al castellano. Junto a este lugar de la Poética, Ponce avala el uso de voces nuevas con los versos 55-58 del Arte Poética de Horacio.

48. "Huius enim fervoris sunt sublimes effectus, ut puta mentem in desiderium dicendi compellere, peregrinas et inauditas inventiones excogitare, meditatas ordine certo componere, ornare compositum inusitato quodam verborum atque sententiarum contextu, velamento fabuloso atque decenti veritatem contegere» (Boccaccio, Genealogia deorum gentilium, 14, 7, 27-32). 
imbenciones, ampliarlas y ornarlas compuestas con vn cierto raro y no común estilo de Palabras supremas y sentencias diuinas, y deuajo el velo de la fábula apropiada, esconder la conocida verdad (Ponce, Discurso, ff. 94v-95r)

Tras estas consideraciones, en general centradas en el especial rango del poeta y su necesaria oscuridad, el Discurso continúa con una serie de ejemplos de poetas en los que la oscuridad es una característica fundamental (ff. 96v-100v). Acaso porque la acumulación es más sencilla que la reflexión, esta línea de carácter compilatorio fue muy seguida en la defensa de Góngora, y menos abundantes las reflexiones sobre el fenómeno que ocupó a Ponce. A cada autor nombrado por Ponce le acompańa una breve caracterización de las causas por las que es difícil y/o una enumeración de los comentarios que necesitaron sus poemas. La sección se organiza cronológicamente:

- (ff. 96v-98r) antiguos: Plauto, Petronio, Séneca, Estacio, Juvenal, Persio, Marcial, Catulo, Tibulo, Geórgicas de Virgilio (que Ponce conoce bien por su Apología), Ausonio Gallo,

- (ff. 98r-100r) vulgares italianos: Dante, Petrarca, Beniveni florentino (Girolamo Benivieni).

-(ff. 100r-100v) vulgares espańoles: Mena, Herrera y Diego de Mendoza. Precisa aquí que los dos últimos no fueron tan oscuros como Góngora, que superó de este modo a sus predecesores.

Tras esta lista, Ponce retoma la digresión sobre la «licencia del poeta para inventar nuevas voces y frases ampliando su natural idioma» (ff. 101r-107v). Es este un asunto tratado con bastante extensión (algo más de un tercio del Discurso) y que también abordó en la Epistola a Villamediana, el texto que defendía al Faetón de quienes lo censuraban por el uso de voces extranjeras. Esta parte del Discurso presenta muchas semejanzas con dicha Epistola a Villamediana, y varios pasajes fueron utilizados por Ponce en ambos lugares. Como la Epistola se fecha entre 1617 y 1622 (aparición del Faetón y asesinato de Villamediana en agosto), parece que la primera incursión en el asunto habría sido la de este Discurso, y que luego Ponce ahondó en el tema a raíz de la aparición del Faetón de Villamediana en 1617. El primer pasaje que comparten ambas obras está tomado de Macrobio (Saturnalia 6, 4, 20-21 y 6, 5, 1-8), como ya advirtieron Rozas y Quilis (1961: 420-421), quienes señalaron que probablemente Ponce lo tomó de una antología ${ }^{49}$.

El segundo pasaje, contiguo al anterior, es copiado también de forma literal en ambas obras, no solo la cita de Cicerón, sino incluso la formulación del propio Ponce:

Cicerón nos muestra claro que las voces se hacen nuebas en vna epist. a Bruto.

Eum amorem et eum, $v$ t hoc verbo vtar fauorem inconsilium aduocabo

donde se ve que en su tiempo fauor era palabra nueba. Y las voces griegas que están

49. En concreto, Ponce cita fragmentos de Saturnalia 6, 4, 20 («daedala tellus»), 6, 4, 21 («nec citara reboant laqueata aurataque tecta»), 6, 5, 2 ("heu Mulciber! / arma ignavo invicta es fabricatus manu») y 6, 5,5 («neque triste quaeritat sinapi / neque cepe maestum»). 
yntroducidas en la latinidad, y se vsaron en ella, son casi ynfinitas, y no solo las voces sino los modos de decir, como vemos en los Poetas latinos que a cada paso ponen los infinitivos por los gerundios, como los griegos que carecen de ellos (Ponce, Discurso f. 105r)

Cicerón nos muestra claro que las boçes se hacen nuebas en vna epístola a Bruto: "Eum amorem et eum, ut hoc verbo vtar favorem inconsilium advoco", donde se be que en su tiempo fabor hera palabra nueba y las boçes griegas que están yntroducidas en la latinidad son casi ynfinitas, y no solo las boçes, sino los modos de decir, como bemos en los poetas latinos, que a cada paso ponen los ymfinitibos por los xerundios, como los griegos, que carecen dellos (Epistola a Villamediana, p. 421)

Esta sección del Discurso se organiza sobre la cita, traducción y glosa de los versos 46-59 del Arte Poética de Horacio, donde se autoriza con diversas razones la incorporación de voces nuevas por parte del poeta. Los requisitos fundamentales manifestados en la poética horaciana eran que, o bien estuviesen compuestas por voces comunes, o bien fuesen tomadas de fuente griega. Ponce señala que Góngora ha cumplido con ambas exigencias: el primero de los requisitos lo atestigua con la voz semicapro, formada de otras comunes y que comentó en la nota 88 a la Soledad primera; el segundo lo argumenta repitiendo la idea de que, igual que los latinos introdujeron esas voces a partir de términos griegos, Góngora hizo lo propio desde las lenguas latina y toscana.

Tras ese comentario a los versos de la epístola horaciana, Ponce (ff. 105v-106v) señala una serie de voces latinas, toscanas y nuevas que fueron introducidas por autores espańoles; en concreto, "el docto Juan de Mena» y "el ingenioso Garcilaso», ambos utilizados ya antes como autoridades en favor de los usos gongorinos. Las voces coinciden con las que señalará en la Epistola a Villamediana (f. 3v). En esta epístola se limita a enumerarlas en una lista: glebas, blasmar, bullada, fontana, almo, inerte, corrusca, nobelo; en el Discurso, las atribuye de manera precisa a los poetas ${ }^{50} \mathrm{y}$ añade un breve comentario sobre su procedencia en cada una de ellas.

Ya cercano el final del Discurso, Ponce recapitula las anteriores observaciones y exculpa a Góngora de todas las acusaciones que se vertieron contra su poesía. Como complemento, remite para más detalles a dos obras que manejó a la hora de abordar los aspectos estilísticos y, sobre todo, el asunto de las voces foráneas e inventadas. La primera de ellas es la edición del Arte Poética de Horacio con anotaciones del Brocense, publicada en Salamanca en $1591^{51}$. Examinando los textos, puede afirmarse que Ponce manejó la écfrasis y notas al apartado De

50. nobelo, nubiferas (que no está en la Epistola), glebas, blasmar y bullada a Juan de Mena; fontana, almo, inerte y corrusca a Garcilaso.

51. Francisci Sanctii Brocensis in incluta Salmanticensi Academia Rhetorices, Graecaeque; linguae Primarii Doctoris. In artem Poeticam Horatii Annotationes. Salmanticae, Apud Ioannem \& Andream Renaut fratres, 1591. Ponce cita los versos 46-59 del Arte Poética de Horacio, y remite al comentario del Brocense, que, en la sección mencionada, abarca esos versos y, como dice Ponce, los 13 siguientes hasta el 72. Su comentario (De auctoribus interpretandis sive de exercitatione) de 1558 no incluía el texto de Horacio. 
iunctura, siue de verborum innovationes quae triplex est, contenidos entre los folios $6 \mathrm{v}$ y $8 \mathrm{v}$ del impreso. La segunda obra es la traducción italiana y notas de la Poética de Aristóteles de Alessandro Piccolomini, cuya primera edición se publicó en Siena en 1572, aunque fue más utilizada la segunda, veneciana, de 1575. Ponce se refiere al apartado dedicado a la virtud o excelencia de la elocución (Poética 1458a18-1459b16, capítulo 22, pp. 208-215 en la edición de García Yebra); en la edición de Piccolomini, comprende el texto y notas a las particellas 116 a 123 (pp. 344-367 en la edición de 1575) ${ }^{52}$.

La conclusión del Discurso es una recapitulación de los méritos de la poesía de Góngora, al tiempo que una llamada a que los estudiosos dediquen sus esfuerzos a examinarla con esmero y no a censurarla, lo que sin duda les llevará al reconocimiento del poema y su autor. La cita de Marcial que cierra el texto (libro 2, epigrama 86, vv. 11-12) es una ya clásica referencia a la poesía exquisita y elitista que se utilizó en la polémica gongorina ${ }^{53}$ :

Asentada esta dotrina, digo que si resulta alguna obscuridad en este escripto, porque imita su autor a los latinos y toscanos en él, antes es justo que sea estudiado que depuesto, porque si la dificultad que tiene no naçe de lo que suele hacer inaccesibles a otros (como e dicho) será justo que los prudentes y doctos, dando el deuido crédito al autor, crean que tiene más de admirable que de molesto, y mirando su gramática con atención, hallarán facilidad en la construcción della, agudeza en sus conceptos, ornato en la locución y valientes imitaciones en ella, con yngeniosa nouedad en los términos y descripciones; y al fin el deleyte de hauer alcanzado lo que sin alguna dificultad careze de estimación, y así podrá decir a todos el autor lo que antes dixo Martial. L2 Epig 86: Scribat carmina circulis Palaemon / me iuuat raris auribus placere (Ponce, Discurso, ff. 108r-108v)

En conclusión, debe situarse a Ponce en los comienzos de una línea de defensa de la poesía de Góngora fundamentada en admitir la oscuridad como rasgo inherente al oficio del poeta. Las dedicatorias que encabezan el texto y notas de la Soledad primera y, sobre todo, el texto del Discurso, muestran en los primeros momentos de la polémica una reflexión sobre el fenómeno de la oscuridad que no siempre se mantuvo en textos posteriores. El tono encendido del enfrentamiento llevó a menudo a refutaciones concretas de escritos, argumentos e interpretaciones de versos que no siempre permitieron dar la debida importancia a la excepción que el quehacer poético supone siempre a los preceptos gramaticales y retóricos, excepción que las propias gramáticas y retóricas reconocían al convertir en licencias poéticas los vicios del lenguaje, y al eximir al poeta de la moderación y mesura que se exigía al ornatus del orador. Ponce parte de ese carácter excepcional del poeta, y desde él resulta una visión de la oscuridad como un rasgo caracterizador de su arte, y no como el vicio opuesto a la perspicuitas que la retórica exigía al orador, y con el que tanto se fustigó a los versos de Góngora.

52. Annotationi di M. Alessandro Piccolomini, nel libro della Poetica d'Aristotele; con la tradvttione del medesimo Libro, in lingua Volgare. Con privilegio, In Vinegia, Presso Giovanni Guarisco, \& Compagni [1575].

53. Así, por ejemplo, en la Soledad primera ilustrada y defendida (Osuna Cabezas, 2009: 82). 


\section{Bibliografía}

Alonso, Dámaso, «Manuel Ponce, primer comentarista de Góngora», en Libro homenaje a Antonio Pérez Gómez, Cieza, 1978, pp. 1-18. Manejo la reimpresión incluida en Dámaso Alonso, Obras completas, Madrid, Gredos, 1982, vol. VI, pp. 501-524.

Angulo y Pulgar, Martín de, Epistolas satisfactorias. Una a las objeciones que opuso a los poemas de D. Luis de Góngora el licenciado Francisco de Cascales, Catedrático de Retórica de la S. Iglesia de Cartagena, en sus Cartas Filológicas. Otra a las proposiciones que contra los mismos poemas escribió cierto sujeto grave y docto, Granada, Blas Martínez, 1635 (ejemplar de la Hispanic Society of America, New York, PQ 6279. A 415 E657 1635).

Aristóteles, Ética a Nicomaco, edición bilingüe y traducción española de María Araujo y Julián Marías, Madrid, Instituto de Estudios Políticos, 1959.

Aristóteles, Poética, edición trilingüe [griego-latín-castellano] de Valentín García Yebra, Madrid, Gredos, 1974.

Aristóteles, Poética, Annotationi di M. Alessandro Piccolomini, nel libro della Poetica d'Aristotele; con la tradvttione del medesimo Libro, in lingua Volgare. Con privilegio, In Vinegia, Presso Giovanni Guarisco, \& Compagni [1575].

Azaustre Galiana, Antonio, "Cuestiones de poética y retórica en los preliminares de Quevedo a las poesías de fray Luis de León", La Perinola. Revista de Investigación Quevediana, 7, 2003, pp. 61-102.

Azaustre Galiana, Antonio, «El uso retórico de las Autoridades en las polémicas literarias sobre el estilo culto", en A zaga de tu huella. Homenaje al profesor Cristóbal Cuevas, vol. 1, ed. de Salvador Montesa, Málaga, Servicio de Publicaciones de la Universidad de Málaga, 2005, pp. 309-333.

Azaustre Galiana, Antonio, «Poesía y retórica en el Siglo de Oro: cuestiones en torno al estilo culto", en Rodrigo Cacho Casal y Anne Holloway, eds., Los géneros poéticos del Siglo de Oro: centros y periferias, Woodbridge, Tamesis Books, 2013, pp. 133-150.

Azaustre Galiana, Antonio y De Carlos Villamarín, Helena, "Apología en defensa de Virgilio, un comentario inédito de Manuel Ponce», Criticón, 110, 2010, pp. 95-132.

Blanco, Emilio, ed., Setantí, Joaquín, Centellas de varios conceptos, Palma de Mallorca, J. de Olańeta y Ediciones de la Universitat de les Illes Balears, 2006.

Blanco, Mercedes, «Ut poesis, oratio. La oficina poética de la oratoria sacra en Hortensio Félix Paravicino», Lectura y signo, 7 (2012), pp. 29-65.

Boccaccio, Giovanni, Genealogie deorum gentilium libri, a cura de Vincenzo Romano, Bari, Laterza, 1951, 2 vols.

Carreira, Antonio, ed., Luis de Góngora, Antología poética, Madrid, Castalia, 1986.

Carreira, Antonio, «La controversia en torno a las Soledades. Un parecer desconocido y edición crítica de las primeras cartas», en Antonio Carreira, Gongoremas, Barcelona, Península, 1998, pp. 239-266.

Carrillo y Sotomayor, Luis, Libro de la erudición poética, edición de Angelina Costa, Sevilla, Alfar, 1987.

Cicerón, Brutus, edición bilingüe [latín-francés] de Jules Martha, Paris, Les Belles Lettres, 1923. 
Cicerón, De Officiis, edición de Michael Winterbottom, Oxford, Clarendon Press, 1994.

Cicerón, De Oratore, edición bilingüe [latín-francés] de Edmond Courbaud y Henri Bornecque, Paris, Les Belles Lettres, 1927-1938, 3 vols.

Codoñer, Carmen, «El modelo filológico de Las Anotaciones», en Begońa López Bueno, ed., Las "Anotaciones» de Fernando de Herrera. Doce Estudios, Sevilla, Secretariado de Publicaciones de la Universidad de Sevilla, 1997, pp. 17-36.

Dadson, Trevor J., «Más datos para la biografía de Don Diego de Silva y Mendoza, conde de Salinas», Criticón, 34, 1986, pp. 5-26.

Dadson, Trevor J., «Un palacio para un conde: la compra y rehabilitación del palacio de Buenavista por Diego de Silva y Mendoza, conde de Salinas", Cuadernos de Historia Moderna, 33, 2008, pp. 61-87.

Dadson, Trevor J., Diego de Silva y Mendoza, poeta y político en la corte de Felipe III, Granada, Editorial Universidad de Granada, 2011.

Dadson, Trevor J., "Luis de Góngora y el conde de Salinas: una curiosa amistad», en Alain Bègue y Antonio Pérez Lasheras, eds., Hilaré tu memoria entre las gentes. Estudios de literatura áurea (en homenaje a Antonio Carreira), Poitiers-Zaragoza, Université de Poitiers-Prensas de la Universidad de Zaragoza, volumen I, pp. 55-78.

Daza Somoano, Juan Manuel, "Alcance doctrinal de las polémicas gongorinas», en Begońa López Bueno, ed., El canon poético en el siglo XVII, Sevilla, Secretariado de Publicaciones de la Universidad de Sevilla, 2010, pp. 125-149.

Daza Somoano, Juan Manuel, «Los testimonios de la polémica epistolar Lope-Góngora (1615-1616), con edición de la Respuesta de Góngora», en Begońa López Bueno, ed., El Poeta Soledad. Góngora 1609-1615, Zaragoza, Prensas Universitarias de Zaragoza, 2011, pp. 239-270.

Daza Somoano, Juan Manuel, «Erudición, autoridades y comentaristas: la polémica gongorina, en los márgenes del canon", en Pedro Ruiz Pérez et alii, eds., Aurea Poesis: estudios para Begoña López Bueno, Córdoba-Sevilla-Huelva, Secretariados y Servicios de Publicaciones de las universidades, 2014a, pp. 287-292.

Daza Somoano, Juan Manuel, "Contexto crítico y polémico de los comentarios manuscritos a las Soledades (1613-1624)», e-Spania. Revue interdisciplinaire d'études hispaniques médiévales et modernes, 18, 2014b.

Egido, Aurora, «La silva en la poesía andaluza del Barroco (con un excurso sobre Estacio y las Obrecillas de Fray Luis)», Criticón, 46, 1989, pp. 5-39.

Entrambasaguas, Joaquín de, «Una guerra literaria del Siglo de Oro: Lope de Vega y los preceptistas aristotélicos», en Joaquín de Entrambasaguas, Estudios sobre Lope de Vega, Madrid, CSIC, 1967, segunda edición corregida y aumentada, 2 vols., vol. 1, pp. 63-580; vol. 2, pp. 11-235.

Fernández de Córdoba, Francisco, Parecer de Don Francisco de Córdoba acerca de las Soledades a instancia de su Autor, en Emilio Orozco, En torno a las «Soledades» de Góngora, Granada, Universidad de Granada, 1969, pp. 130-145.

Fernández de Córdoba, Francisco, Examen del Antídoto o Apología por Las Soledades de Don Luis de Góngora contra el autor de El Antídoto (1617), en Miguel Artigas, Don Luis de Góngora y Argote. Biografía y estudio crítico, Madrid, Real Academia Española, 1925, pp. 400-467. 
Gaillard, Claude, L'action de Diego de Silva y Mendoza, Grenoble, Université des Langues et Lettres, 1983.

González Barrera, Julián, La Expostulatio Spongiae. Fuego cruzado en nombre de Lope, Kassel, Reichenberger, 2011.

Gutiérrez Arranz, Lidia, El universo mitológico en las fábulas de Villamediana, Kassel, Reichenberger, 2001.

Horacio, Arte Poética, ed. bilingüe [latín-español] de Aníbal González, Madrid, Taurus, 1987.

Iglesias Feijoo, Luis, "Una carta inédita de Quevedo y algunas noticias sobre los comentaristas de Góngora, con Pellicer al fondo», Boletín de la Biblioteca de Menéndez Pelayo, 59, 1983, pp. 141-203.

Jammes, Robert, ed., Luis de Góngora, Soledades, Madrid, Castalia, 1994.

Jáuregui, Juan de, Antídoto contra la pestilente poesía de las "Soledades", edición de José Manuel Rico García, Sevilla, Universidad de Sevilla, 2002.

Jáuregui, Juan de, Discurso poético. Advierte el desorden y engaño de algunos escritos, edición de Melchora Romanos, Madrid, Editora Nacional, 1978.

Jiménez Calvente, Teresa, «Virgilio y sus comentarios renacentistas (I)», Estudios clásicos 120, 2001, pp. 35-64.

López Bueno, Begoña, «El cruce epistolar entre Lope y Góngora de 1615-1616. Revisión de fechas», en Begońa López Bueno, ed., El Poeta Soledad. Góngora 16091615, Zaragoza, Prensas Universitarias de Zaragoza, 2011, pp. 239-270.

López Bueno, Begońa, "Las Advertencias de Almansa y Mendoza, el "apócrifo correspondiente" de Góngora», Criticón, 116, 2012a, pp. 5-27.

López Bueno, Begońa, “Con poca luz y menos disciplina”: Góngora contra Jáuregui en 1615 o los antídotos al Antídoto», en Antonio Gargano, dir. María D’Agostino y Flavia Gherardi, eds., Difícil cosa el no escribir sátiras. La sátira en verso en la España de los Siglos de Oro, Vigo, Editorial Academia del Hispanismo, 2012, pp. 205-226.

Macrobio, Saturnalia, edición de R. A. Kaster. Oxford-New York, Oxford University Press, 2011.

Marcial, Marco Valerio, Epigrammes, edición bilingüe [latín-francés] de H. J. Izaac, Paris, Les Belles Lettres, 1930-1933, 3 vols.

Mazzochi, Giuseppe, «Los comentarios virgilianos del Padre Juan Luis de la Cerda», en M. García Martín, ed., Estado actual de los estudios sobre el Siglo de Oro. Actas del II Congreso Internacional de Hispanistas del Siglo de Oro, Salamanca, Universidad de Salamanca, 1993, pp. 663-675.

Orozco Díaz, Emilio, En torno a las «Soledades» de Góngora. Ensayos, estudios y edición de textos criticos de la época referentes al poema, Granada, Universidad, 1969.

Osuna Cabezas, María José, Góngora vindicado: Soledad primera, ilustrada y defendida, Zaragoza, Prensas Universitarias de Zaragoza, 2009.

Pérez Lasheras, Antonio, «La crítica literaria en la polémica gongorina», en Antonio Pérez Lasheras, Piedras preciosas... Otros aspectos de la poesía de Góngora, Granada, Editorial Universidad de Granada, 2009, pp. 77-106.

Piccirillo, Federica, «Edizioni», en Enciclopedia virgiliana, Roma, Istituto della Enciclopedia Italiana, cop. 1984-1990, 5 vols., vol. 2, 1985, pp. 169-178. 
Piccolomini, Alessandro, Annotationi di M. Alessandro Piccolomini, nel libro della Poetica d'Aristotele; con la tradvttione del medesimo Libro, in lingua Volgare. Con privilegio, In Vinegia, Presso Giovanni Guarisco, \& Compagni [1575].

Ponce, Manuel, Epistola de Manuel Ponce al conde de Villamediana en defensa del léxico culterano, véase Rozas, Juan Manuel y Quilis, Antonio.

Quevedo, Francisco de, Comento contra setenta y tres estancias que don Juan Ruiz de Alarcón ha escrito..., en Obras completas. Prosa, edición de Felicidad Buendía, Madrid, Aguilar, 1986, pp. 398-407.

Quevedo, Francisco de, Perinola, en Prosa festiva completa, edición de Celsa Carmen García Valdés, Madrid, Cátedra, 2007², pp. 468-508.

Quevedo, Francisco de, Preliminares literarios a las poesías de fray Luis de León, edición de Antonio Azaustre Galiana en Obras completas en prosa, dirección de Alfonso Rey, Madrid, Castalia, 2003, volumen 1, tomo 1, pp. 119-161.

Quintiliano, Institutio Oratoria, edición bilingüe [latín-francés] de Jean Cousin, Paris, Les Belles Lettres, 1975-1980, 7 vols.

Rhetorica ad Herennium, edición bilingüe [latín-francés] de Guy Achard, Paris, Les Belles Lettres, 1989.

Rico García, José Manuel, ed., Juan de Jáuregui, Antídoto contra la pestilente poesía de las «Soledades», Sevilla, Universidad de Sevilla, 2002.

Roses Lozano, Joaquín, Una poética de la oscuridad. La recepción crítica de las «Soledades» en el siglo xvii, Madrid/Londres, Tamesis Books, 1994.

Rozas, Juan Manuel, y Antonio Quilis, «Epístola de Manuel Ponce al conde de Villamediana en defensa del léxico culterano", Revista de Filología Española, 44, 1961, pp. 411-423.

Sánchez de las Brozas, Francisco, Francisci Sanctii Brocensis in incluta Salmanticensi Academia Rhetorices, Graecaeque; linguae Primarii Doctoris. In artem Poeticam Horatii Annotationes. Salmanticae, Apud Ioannem \& Andream Renaut fratres, 1591.

Tubau, Xavier, Lope de Vega y las polémicas literarias de su época: Pedro de Torres Rámila y Diego de Colmenares, Tesis Doctoral dirigida por Alberto Blecua, Departament de Filologia Espanyola i Teoria de la Literatura, Universitat Autònoma de Barcelona, 2008.

Tubau, Xavier, Una polémica literaria. Lope de Vega y Diego de Colmenares, Madrid/ Frankfurt am Main, Iberoamericana/Vervuert, 2007. 